البحث السادسر:

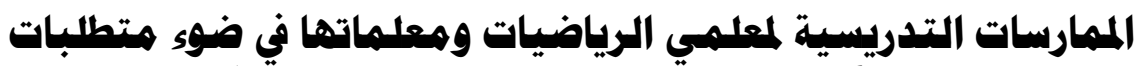

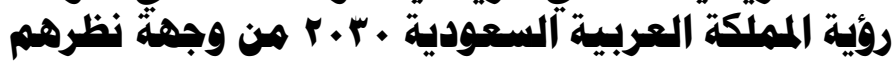

\title{
إعطاق :
}

د/ إبراهيم بن الحسين خليل

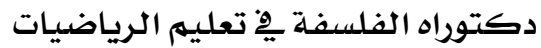

إدارة تعليهم صبيـا بالمملكة الفيلة العربية الريافية

السعودية السية
أ/ عمر سعد عمر التمران

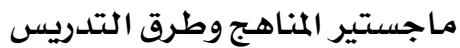

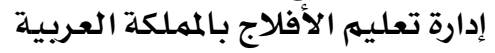

السعودية الافية 



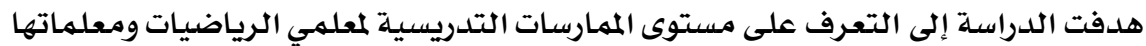

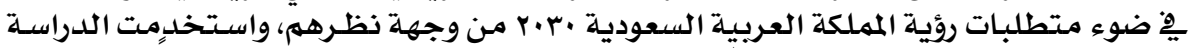

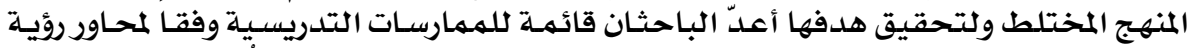

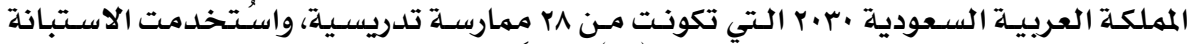

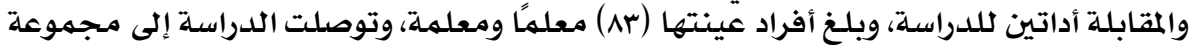

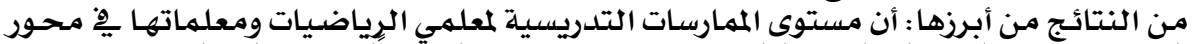

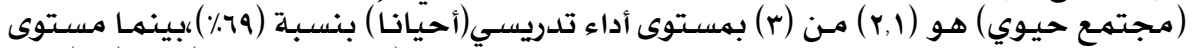

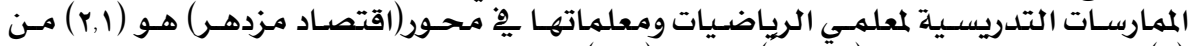

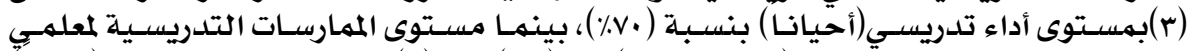

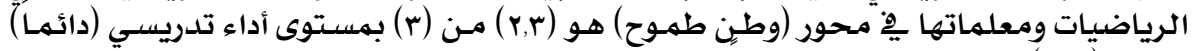

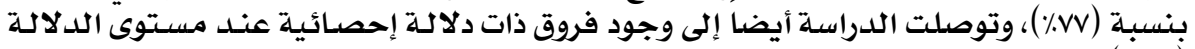

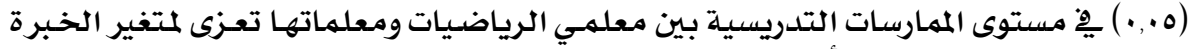

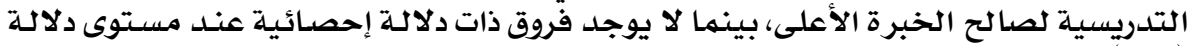

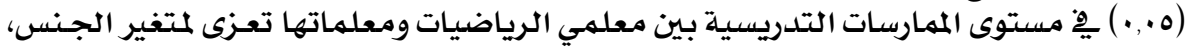

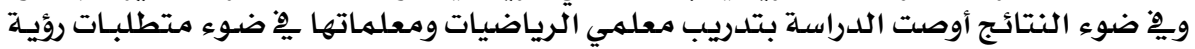

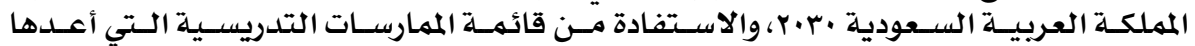

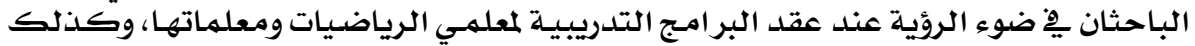

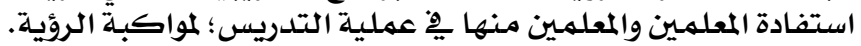

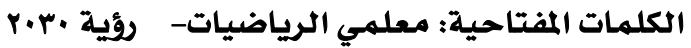

The Educational Practices of Mathematics Teachers Inlight of the Requirements of Saudi Arabia Vision 2030 from Their point of view

\section{Omar Saad Al-Tamran \& Dr. Ibrahim Bin Al-Houssain Khalil}

\section{Abstract:}

This study aims to identify the level of the educational practices of mathematics teachers in light of the requirements of Saudi Arabia Vision 2030 from their point of view. This study uses the Mixed Methods approach. The researchers compiled a list of educational practices, according to the vision of Saudi Arabia 2030. This list consisted of $28^{\text {th }}$ educational practices. Researchers used questionnaires And Interview tools. The study sample consisted of $83^{\text {rd }}$ teachers. The most important for the study are the level of the educational practices of mathematics teachers in the axis of a vital society (2.1) of (3) performance level (sometimes) and by (69\%). While the level of the educational practices of mathematics teachers 


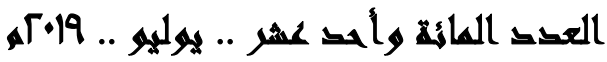

was at the axis of a prosperous economy (2.1) of (3) performance level (sometimes) by $70 \%$. At the same time, the level of educational practices of mathematics teachers in the axis of a prosperous economy is (2.3) of (3) level of performance (permanent) and by (77\%). The study also found statistically significant differences at the level of significance (0.05) in the level of educational practices among mathematics teachers. These differences due to variable educational experience. At the same time, there were no statistically significant differences at the level of significance (0.05) in the level of educational practices among mathematics teachers because of the variable of gender.In the light of the previous results, the study recommended the training of mathematics teachers in light of the requirements of the vision of Saudi Arabia 2030. The study recommended using the list of educational practices for the current study in light of the vision of the Kingdom. This benefit is when holding training programs for mathematics teachers, and in the process of teaching; to keep up with the vision.

Keywords: Mathematics Teachers - Vision 2030

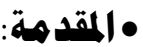

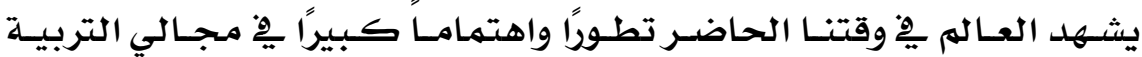

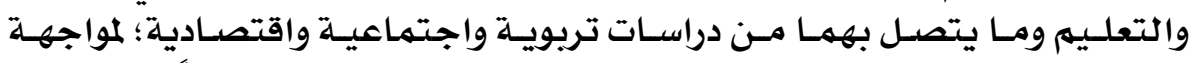

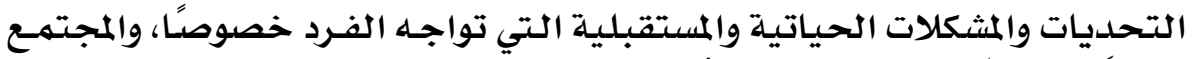

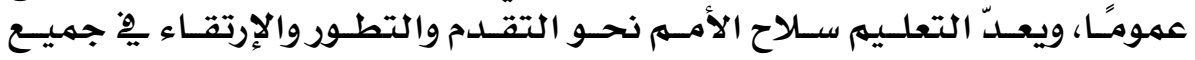

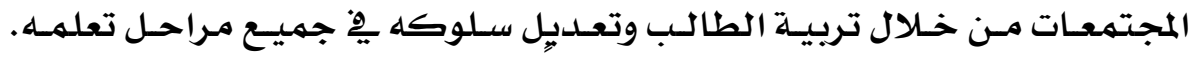

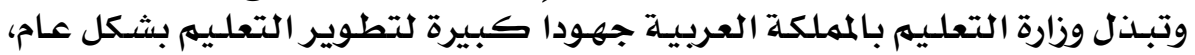

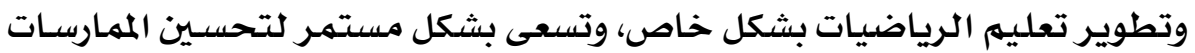

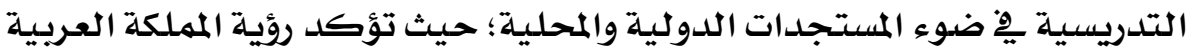

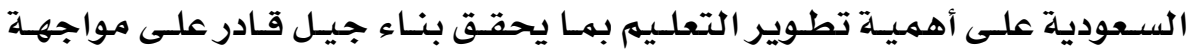

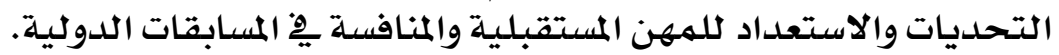

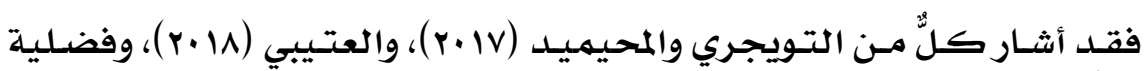

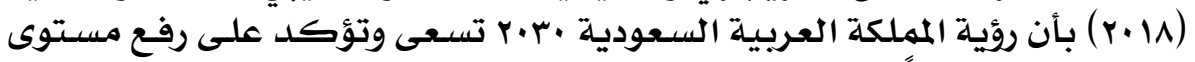

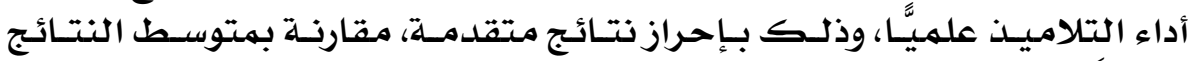

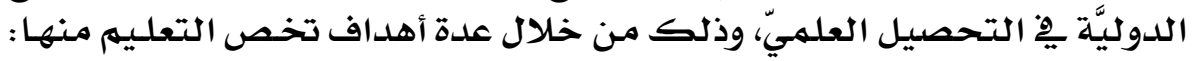

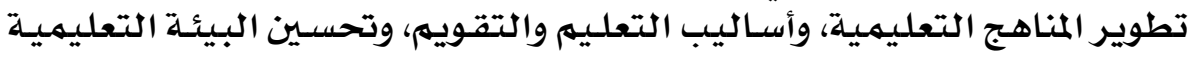

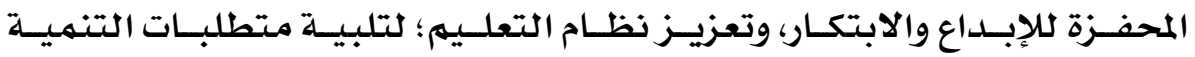

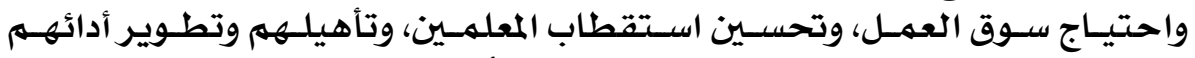

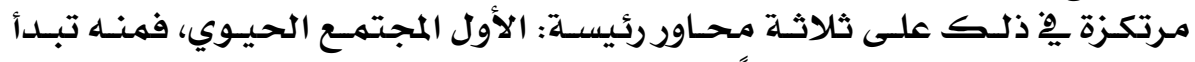

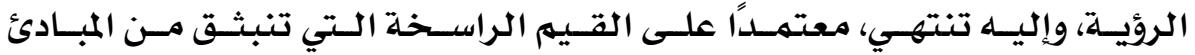

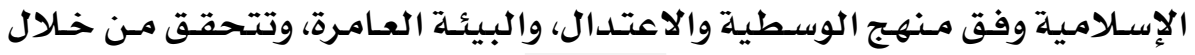




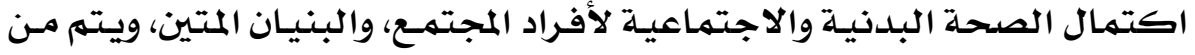

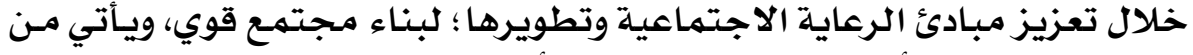

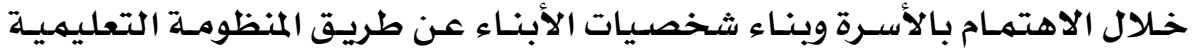

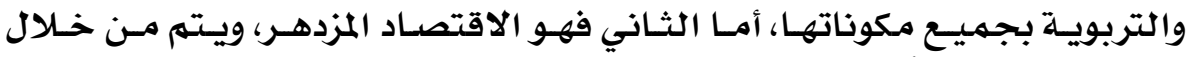

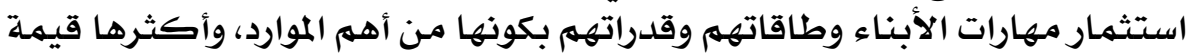

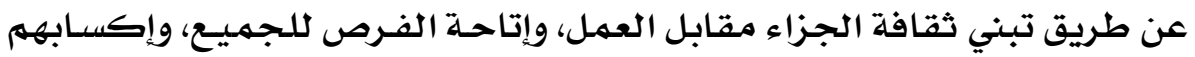
المهارات الالازمة التي تهكنهم مـن السعي نحو تحقيق أهدافهم، والثالث هو الـوطن

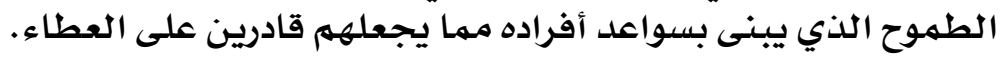

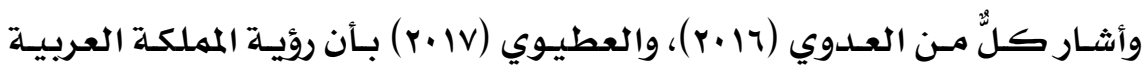

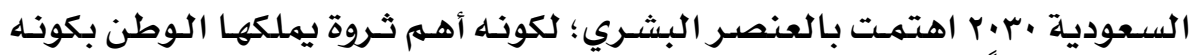

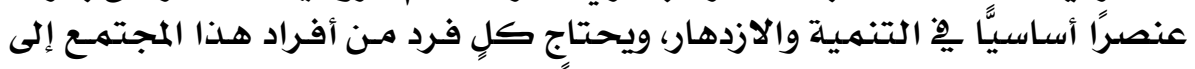

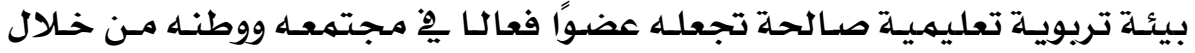

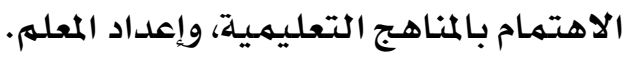

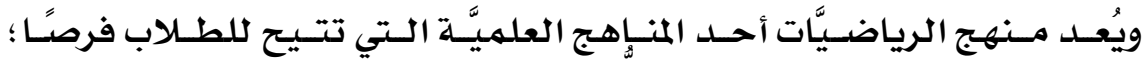

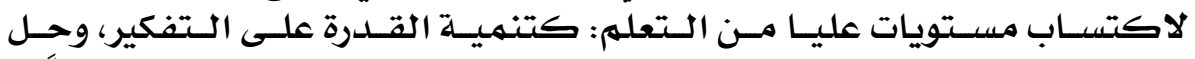

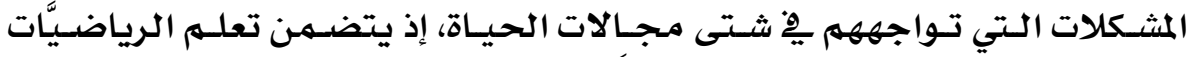

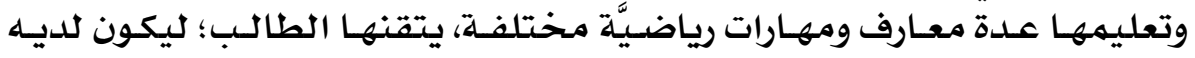

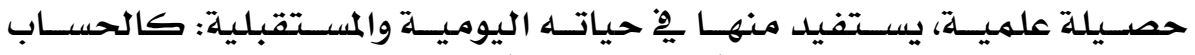

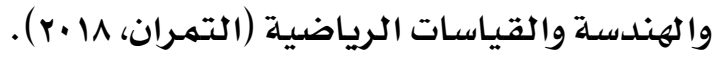

لذلك فإن للهعلهم دورًا كبيرًا يـ تنشئهة أفراد هذا الوطن، وعليه تُبنى الآمـال

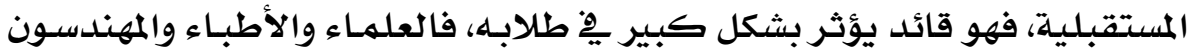

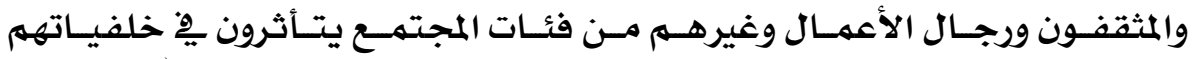

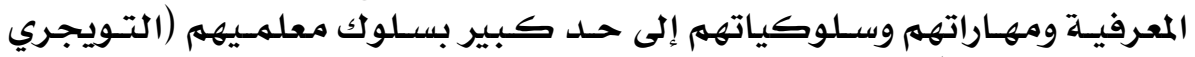

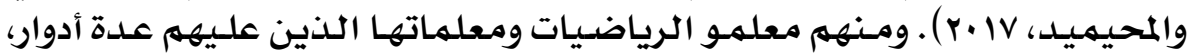

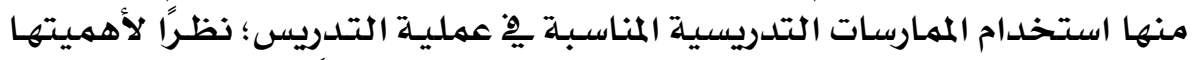

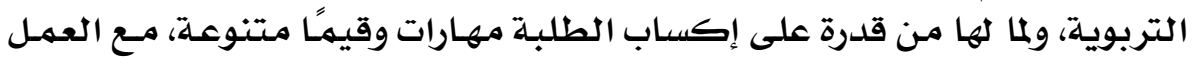

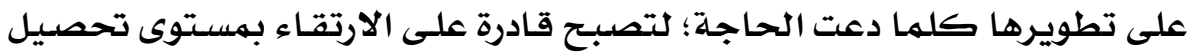

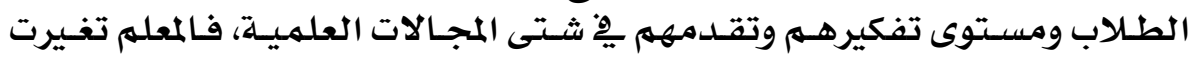

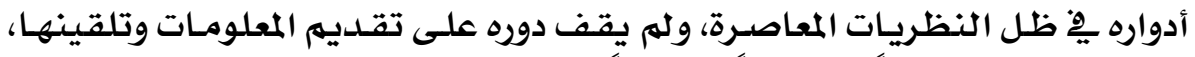

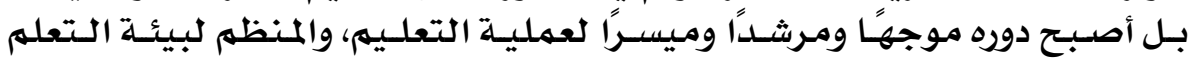

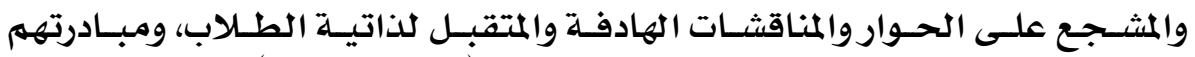

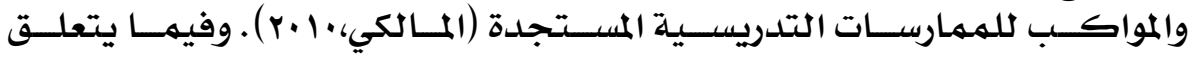

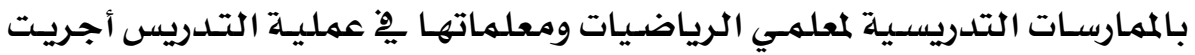




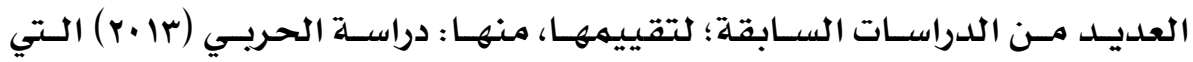

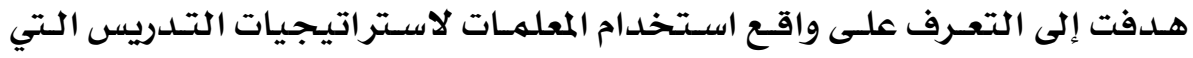

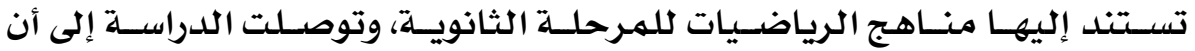

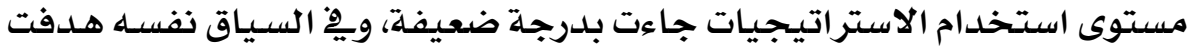

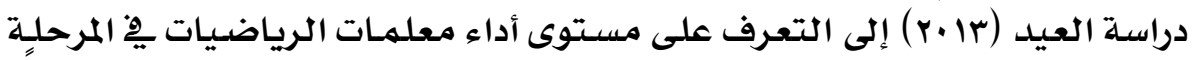

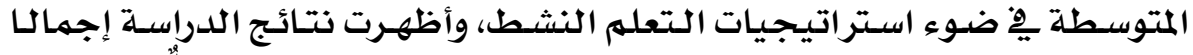

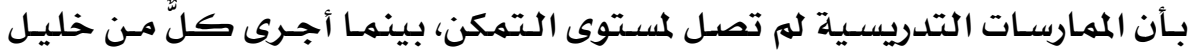

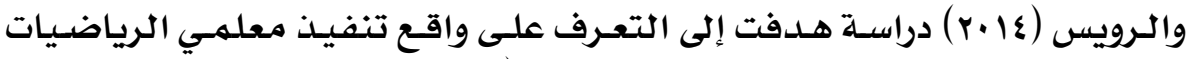

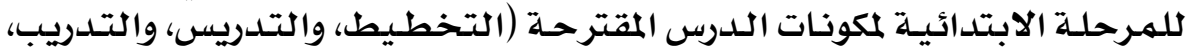

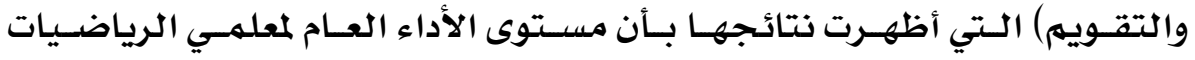

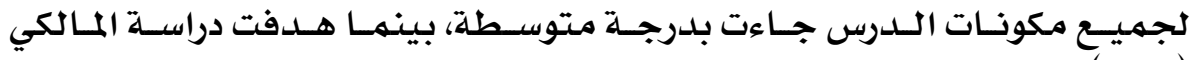

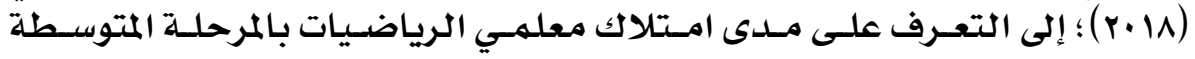

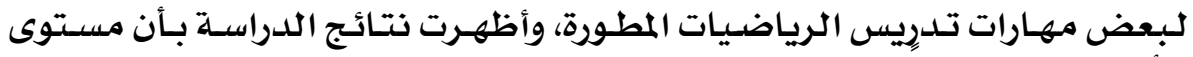

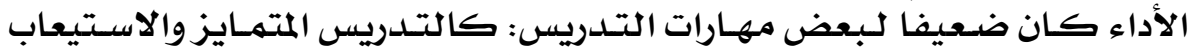

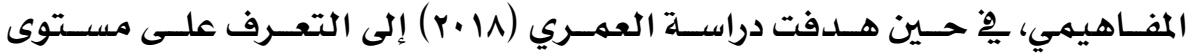

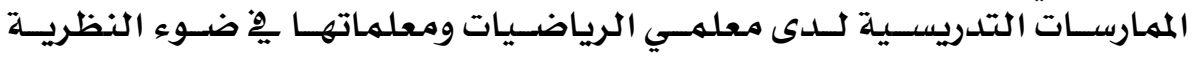

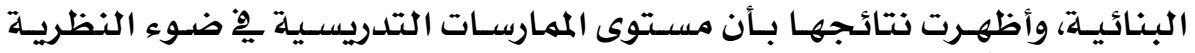

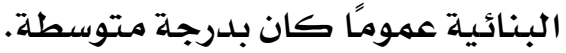

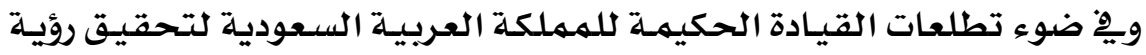

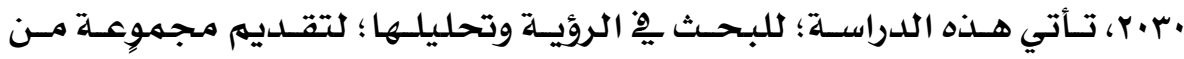

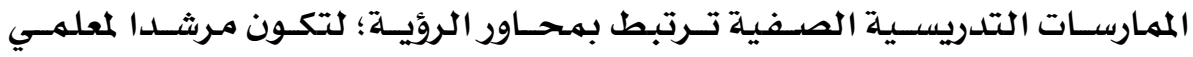

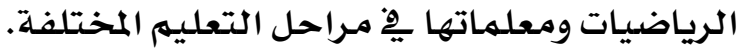

•

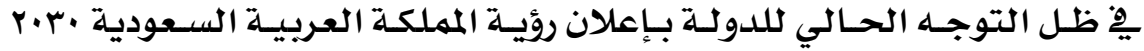

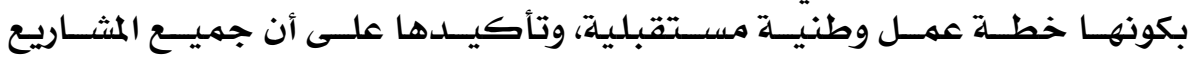

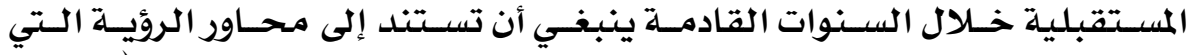

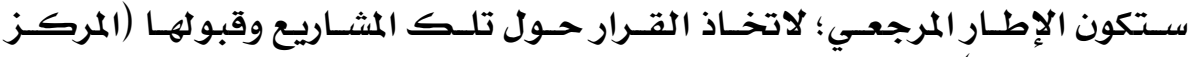

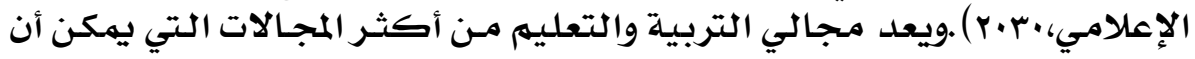

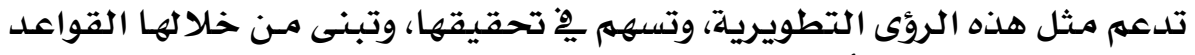

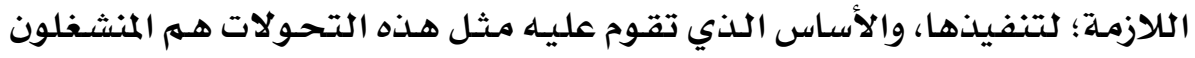

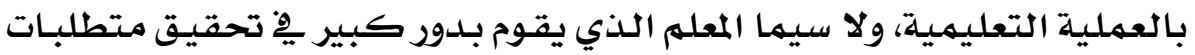

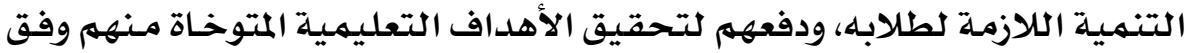

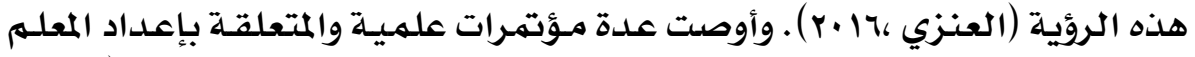

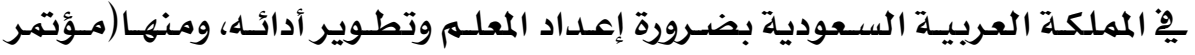




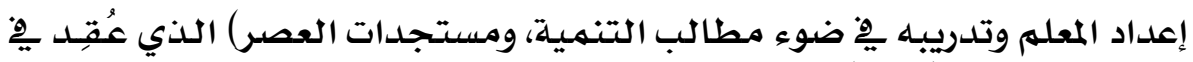

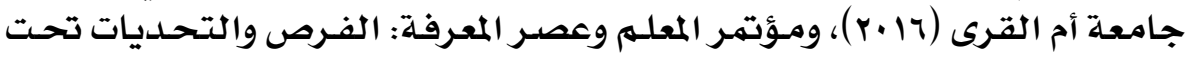

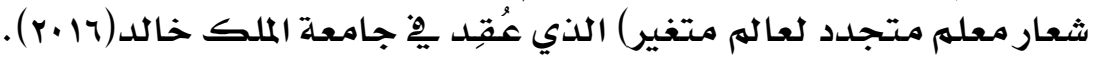

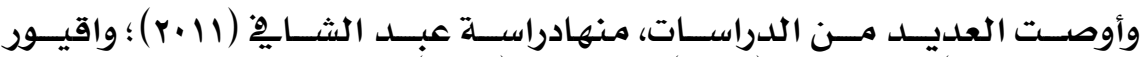

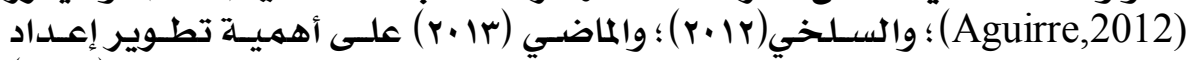

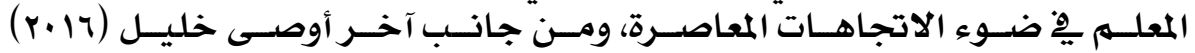

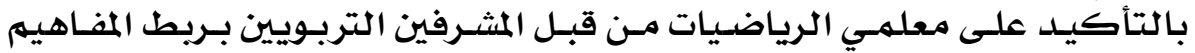

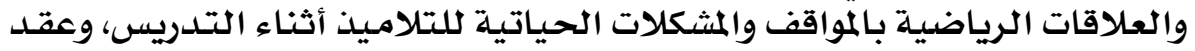

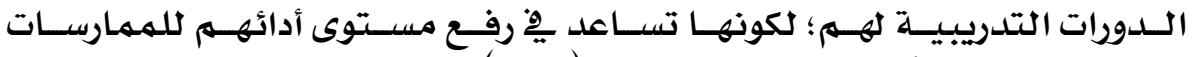

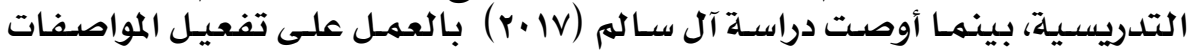

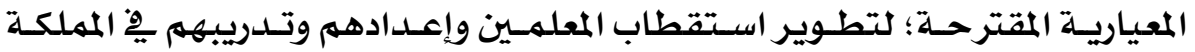

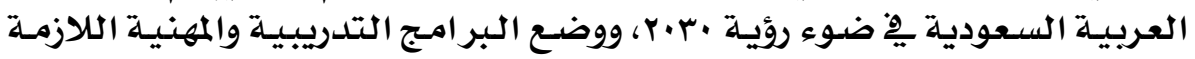

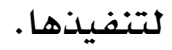

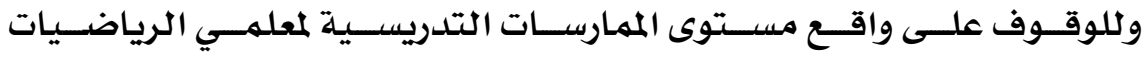

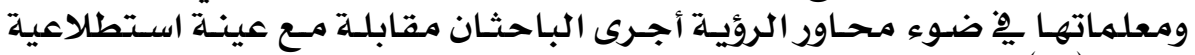

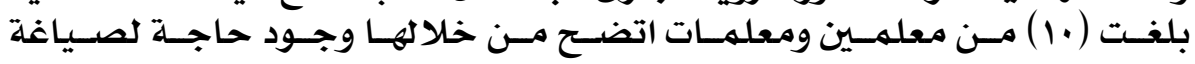

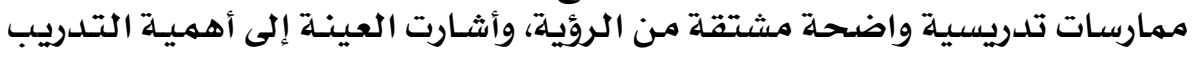

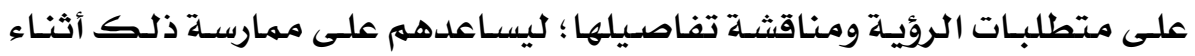

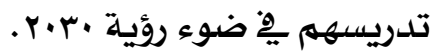

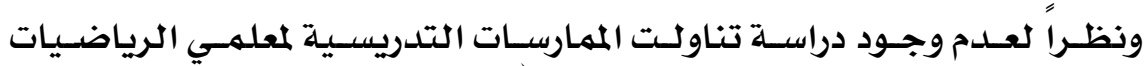

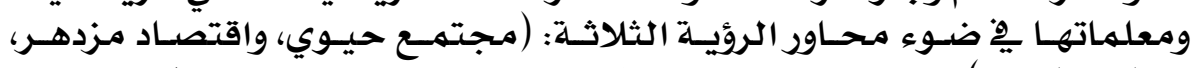

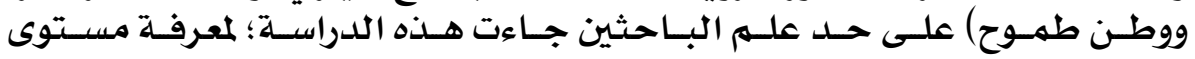

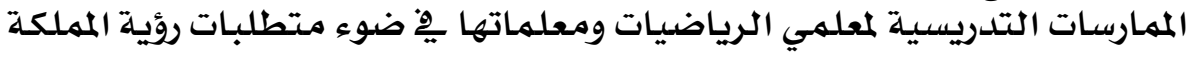

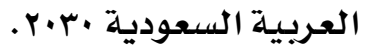

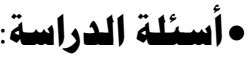

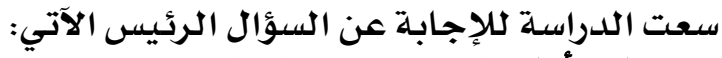

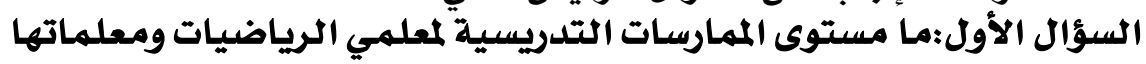

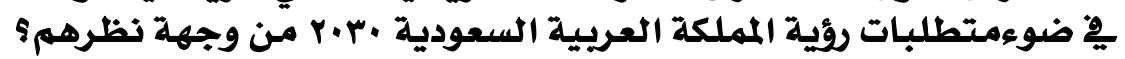
ويتفرع منـه الأسئلة التالية:

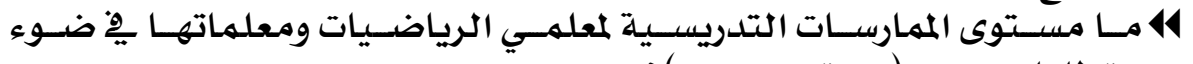

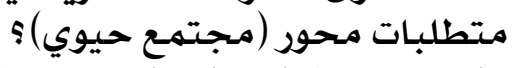

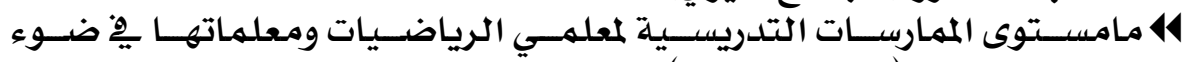

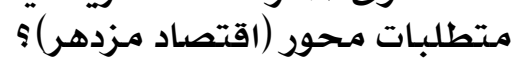

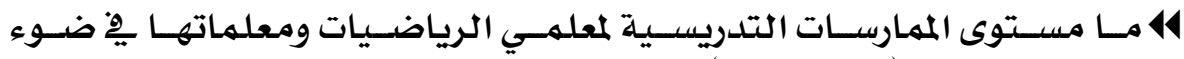

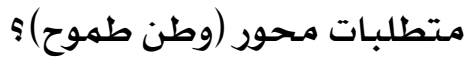




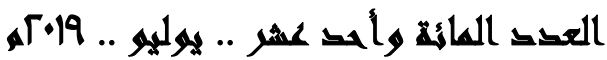

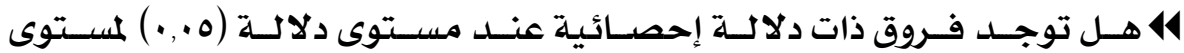

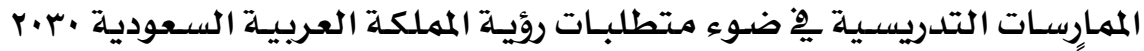

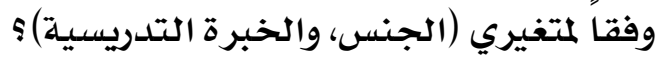

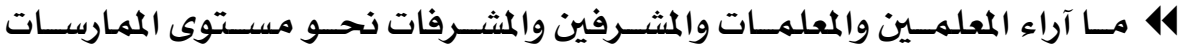

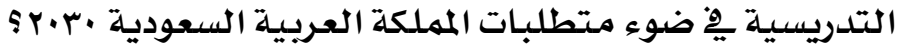

• أهداف الدراستة:

سعت الدراسة لتحقيق الأهداف التحالية:

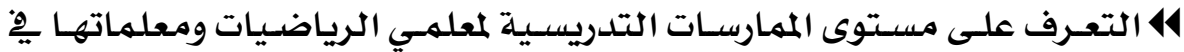

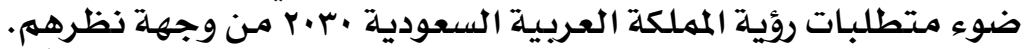

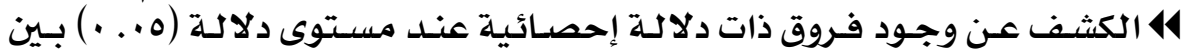

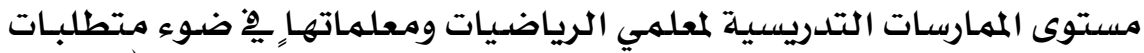

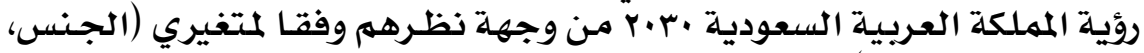
والخبرة التدريسية).

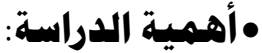

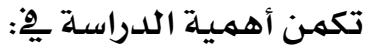

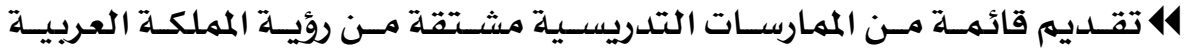

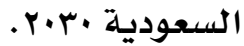

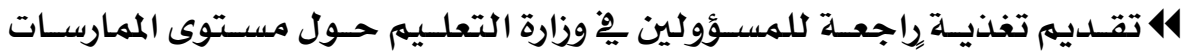

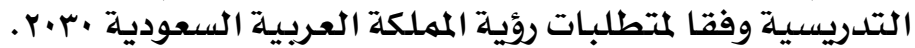

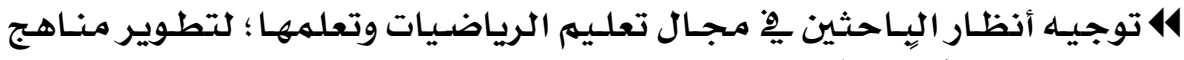

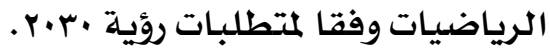

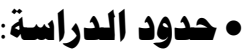

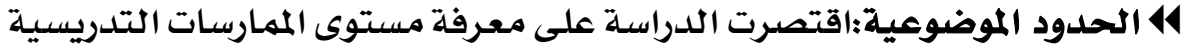

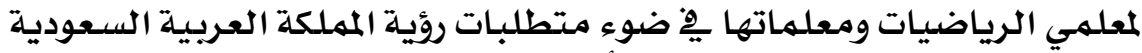

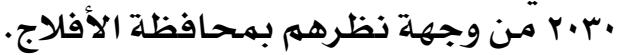

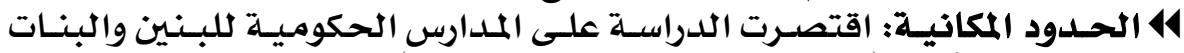

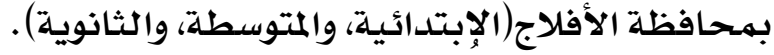

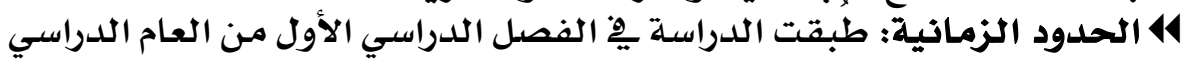

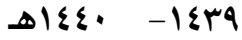

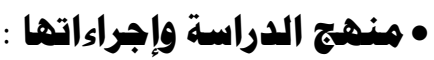

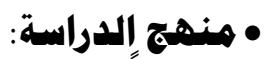

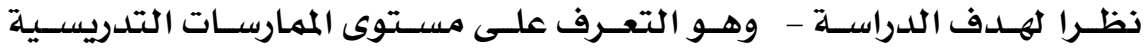

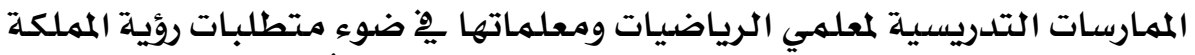

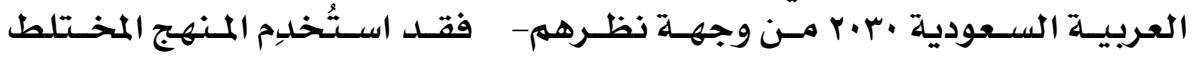

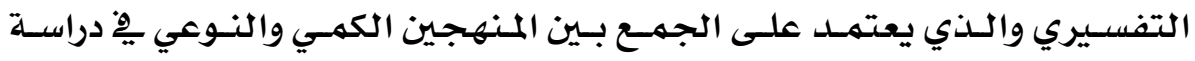

\section{$Y \cdot \varepsilon$}




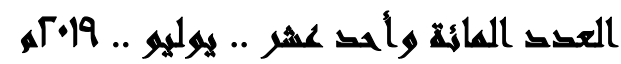

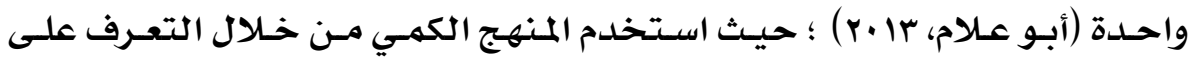

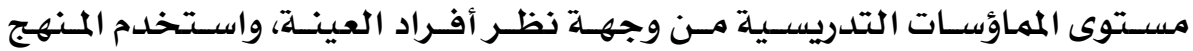

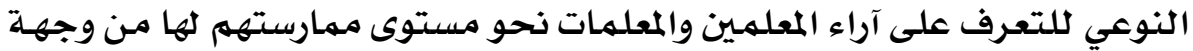
نظرمهرم

\section{• همتسمع الدراسة:}

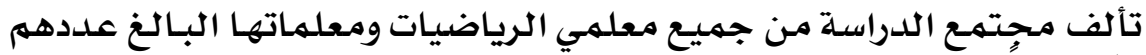

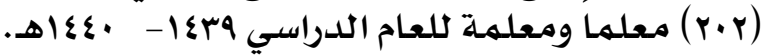

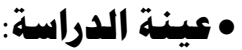

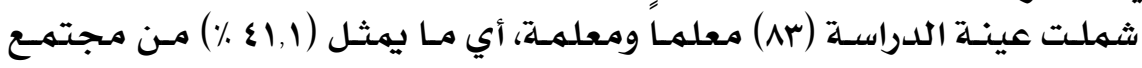
الدراسـة، إذ اختيرت بالطريقة العشوائية.

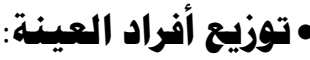 \\ • توزيع أفراد العينة وفقاً لمتغير الجنس:}

جلدول (1) عدد أفراد العينة وفقا لمتغير الجنس:

\begin{tabular}{|c|c|c|}
\hline النسبت المئويت & التكرار & الجنس \\
\hline rV,ro & m & ذكر \\
\hline Tr, 70 & or & أنثى \\
\hline$\%$ & Ar & المججموع \\
\hline
\end{tabular}

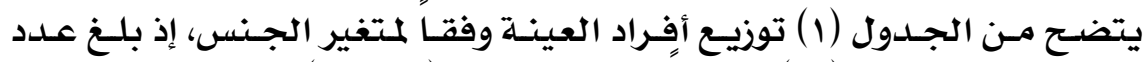

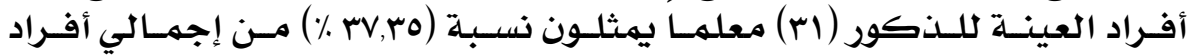

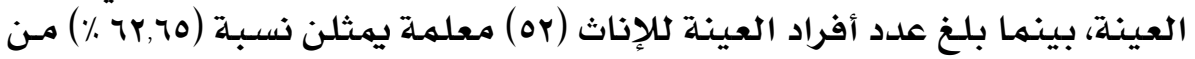

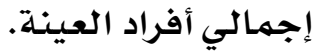

• ب-توزيع أفراد العينة لمتفير سنوات الفبرة التدريسية:

جلدول (r) علدد أفراد العينة وفقا لمتغير سنوات الخبرة التلدريسية:

\begin{tabular}{|c|c|c|}
\hline النسبت المئويت & التكرار & سنوات الخبرة التدريسيت \\
\hline $71,\{0$ & 01 & • إسنوات فأقل \\
\hline ra,00 & rr & أكثر من ·1 سنوات \\
\hline$\%$ & $\wedge r$ & المجموع. \\
\hline
\end{tabular}

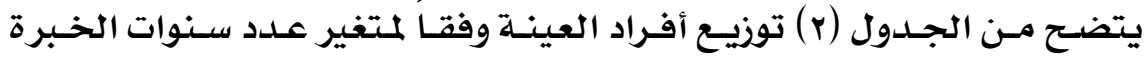

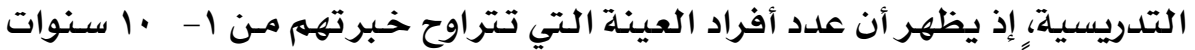

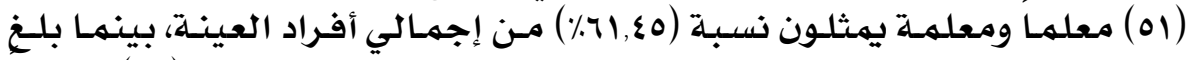

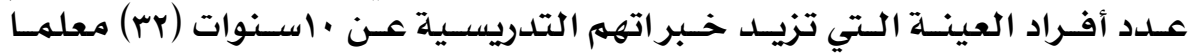

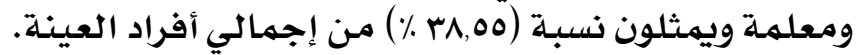




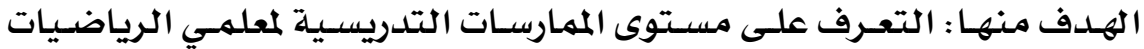

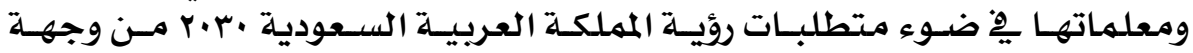
نظرهم. • • إجراءات بناء بطاقة الاستبانة:

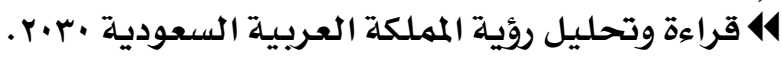

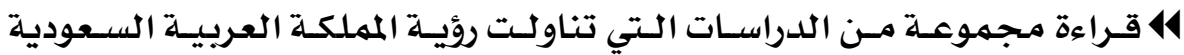
r.r.

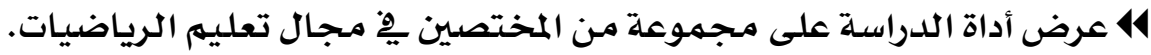

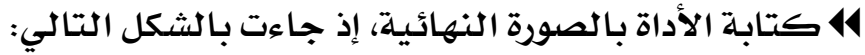

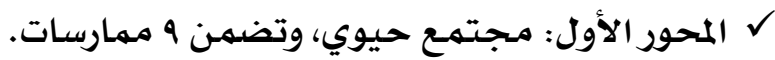

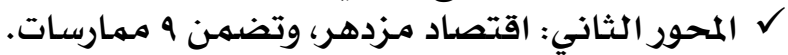

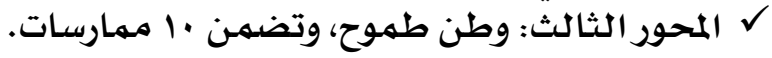

• صدق بطاقة الاستبانة وثباتها:

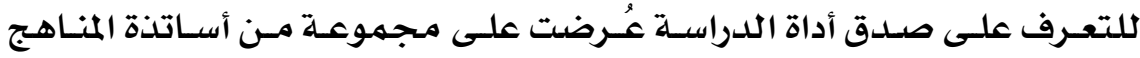

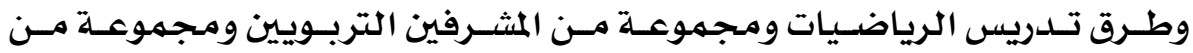

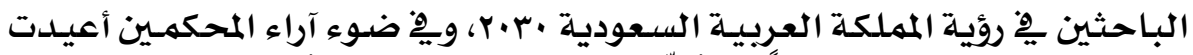

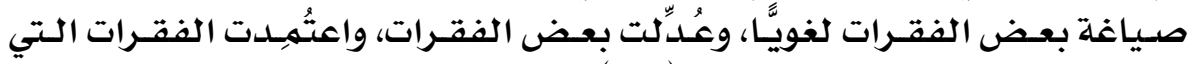

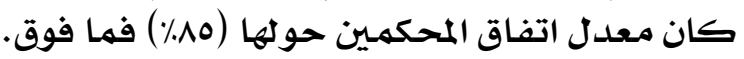

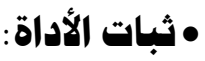

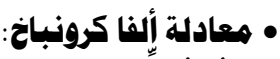

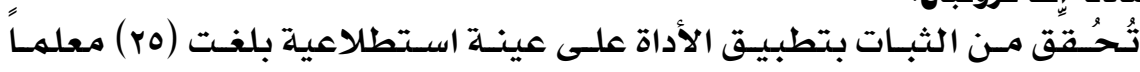

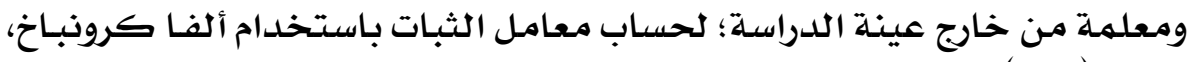

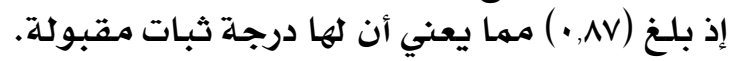

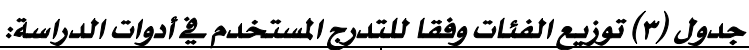

\begin{tabular}{|c|c|}
\hline مدى المتوسطات & مستوى الأداء \\
\hline$r, \cdots-r, r T$ & دائماً \\
\hline r,YO-1,01 & أحياناً \\
\hline $1,0 \cdot \cdots, V_{7}$ & نادراً \\
\hline , vo. & لا أقوم بذلك \\
\hline
\end{tabular}




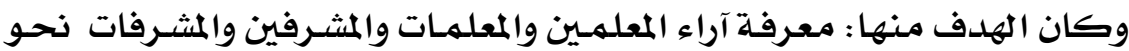

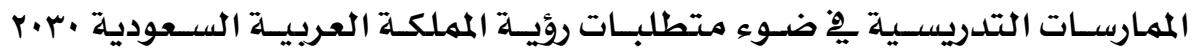

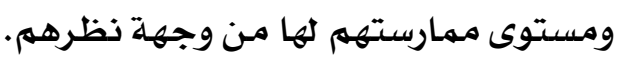
•إجراءات الإقابلة:

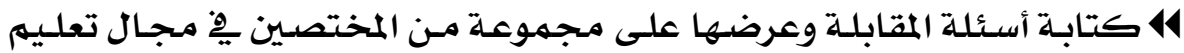

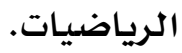

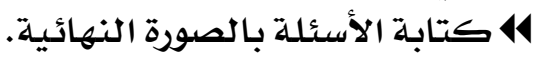

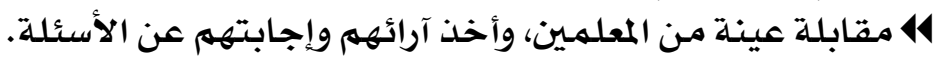

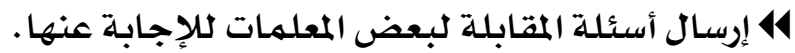

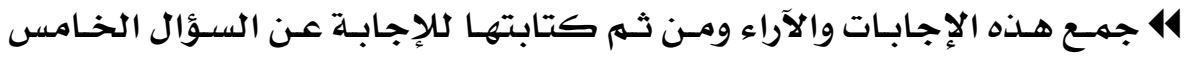
للدراسة الحالية.

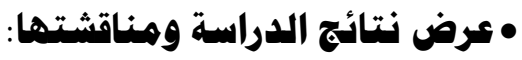

• أولا: النتائج المتعلقة بالسؤال الأول:

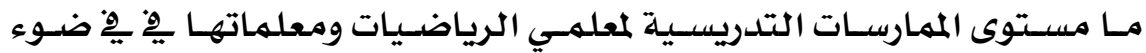

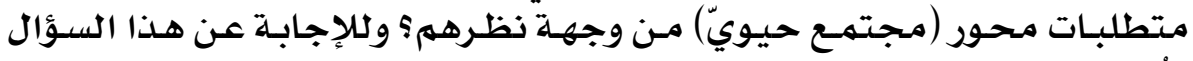

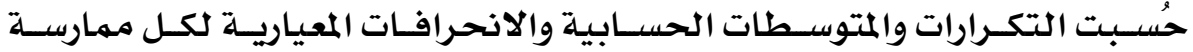

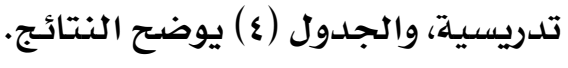

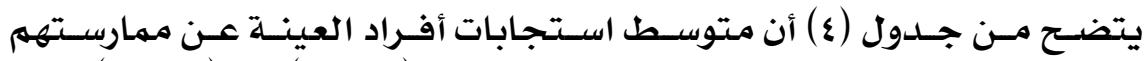

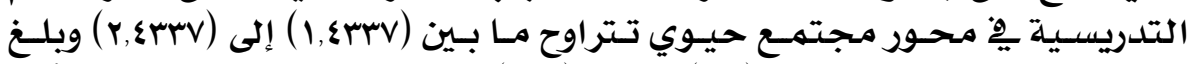

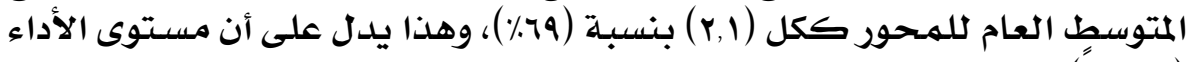
(أحياناً) (أمتوسد)

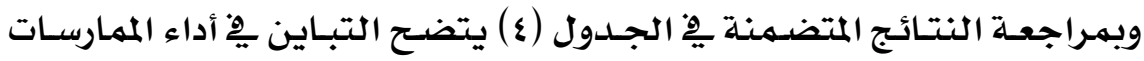

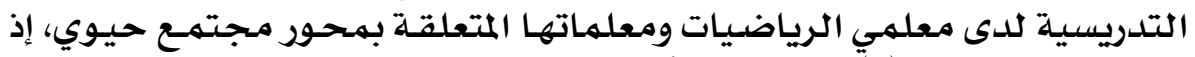

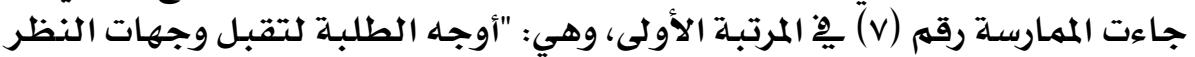

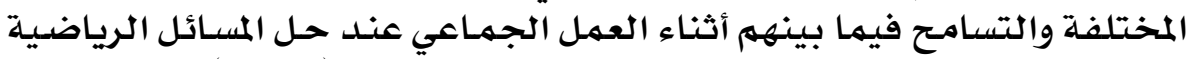

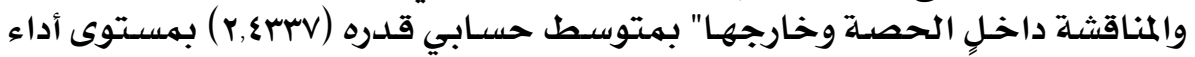

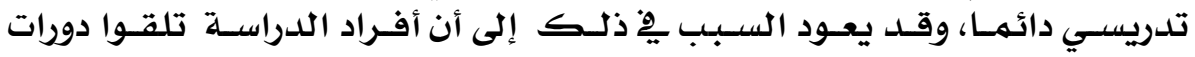

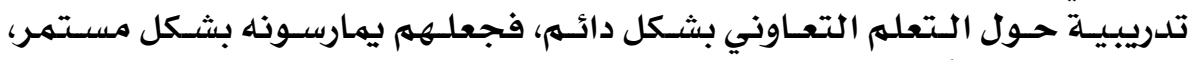

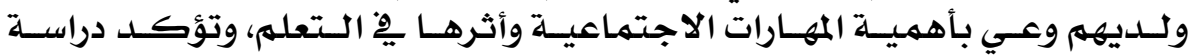
(Avaria,2013)

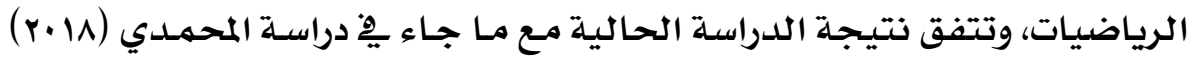

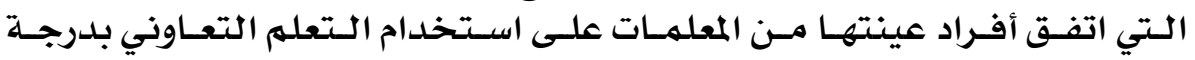




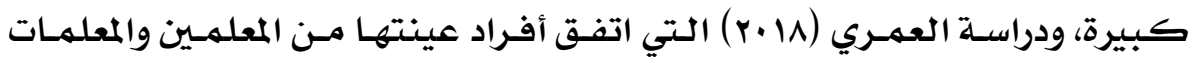

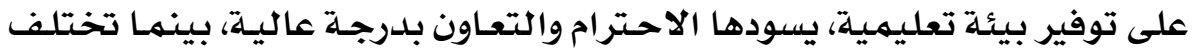

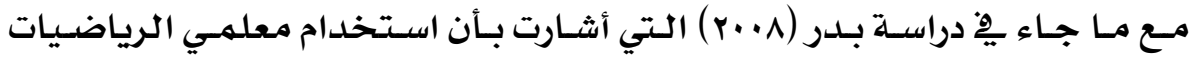

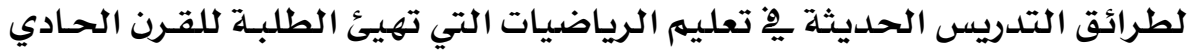

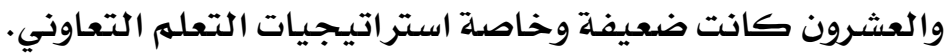

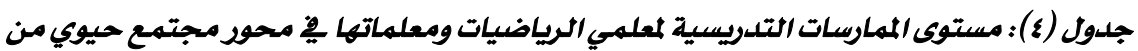
وجهة نظرهم:

\begin{tabular}{|c|c|c|c|c|c|c|c|c|}
\hline \multirow[b]{2}{*}{ مسبتوى الأداء } & \multirow[b]{2}{*}{ الالمعياري } & \multirow[b]{2}{*}{ متوبط الأداء } & \multicolumn{4}{|c|}{ مستوى الأداء } & \multirow[b]{2}{*}{ الممارست } & \multirow[b]{2}{*}{ p } \\
\hline & & & بذلام & نادراً & أحيا & دائماً & & \\
\hline أحياناً & , VTrYI & r.17AV & $r$ & ir & rq & $r$. & 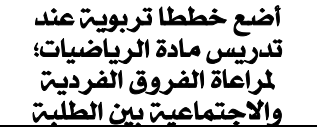 & 1 \\
\hline دائماً & 保AEY & r,rYro & • & $v$ & rA & rı & 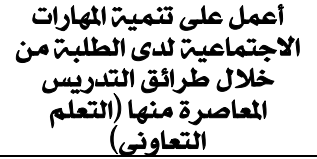 & $r$ \\
\hline أحياناً & •,AIV乏7 & 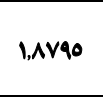 & $\varepsilon$ & YI & rq & 19 & 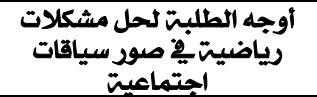 & $r$ \\
\hline أحياناً & ,90rrI & $1,00 \leqslant Y$ & 1E & rr & $r \varepsilon$ & ir & 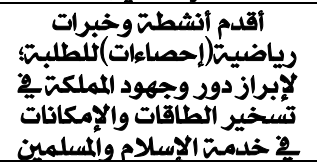 & $\varepsilon$ \\
\hline دائماً & ,OVO\&A & Y,rTlE & - & $\varepsilon$ & \&o & $r \varepsilon$ & 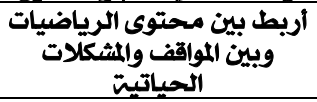 & 0 \\
\hline نادراً & $1,+59 \wedge 9$ & l,ErrV & YI & 19 & rq & $1 \varepsilon$ & 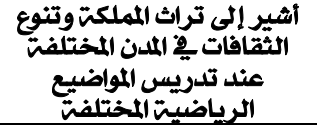 & 7 \\
\hline دائماً & ;,Al\&rq & Y,EYrV & $r$ & $\wedge$ & $r r$ & 0. & 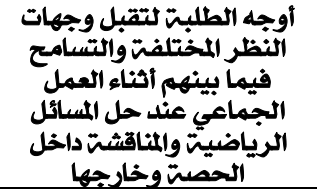 & $v$ \\
\hline أحياناً & $\cdot, \wedge \varepsilon T \cdot \vee$ & Y,T.Y.Y & • & ir & rq & rV & 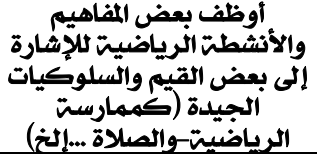 & $\wedge$ \\
\hline دائماً & ;,AYVYE & Y,YTOI & $r$ & IE & $r V$ & $\varepsilon$. & 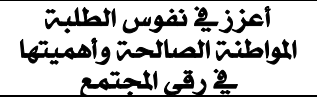 & 9 \\
\hline \multicolumn{2}{|c|}{ أحياناً } & r.1 & & & & & المتوسط & \\
\hline
\end{tabular}




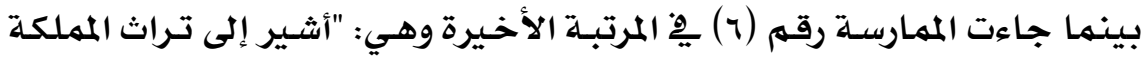

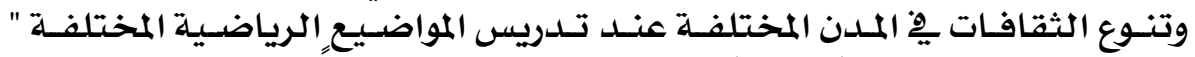

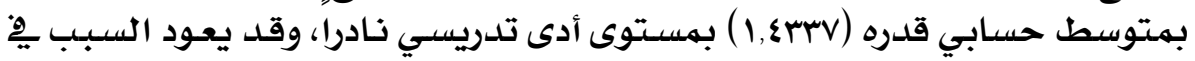

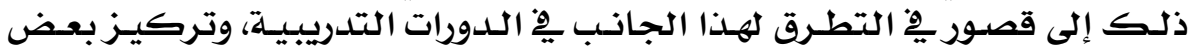

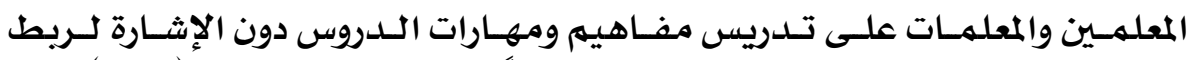

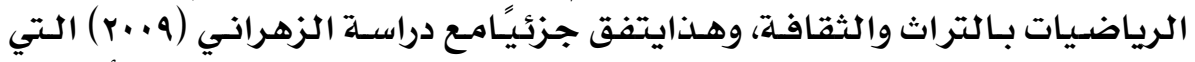

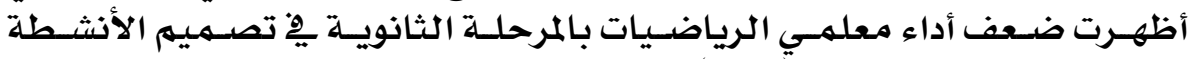

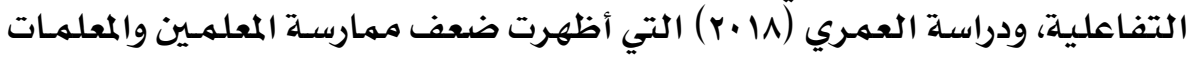

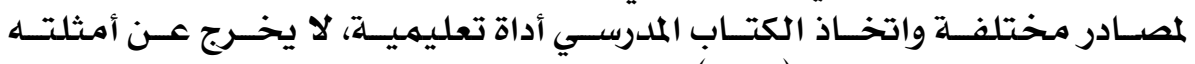

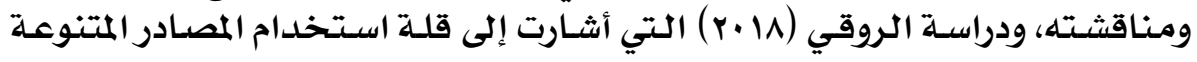

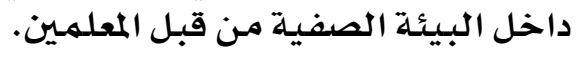

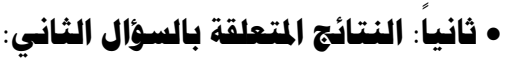

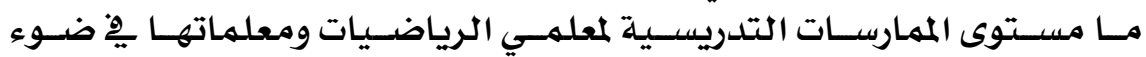

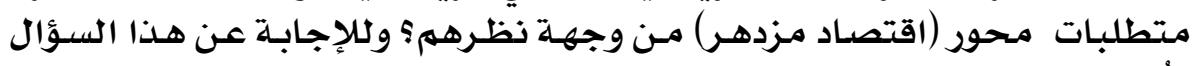

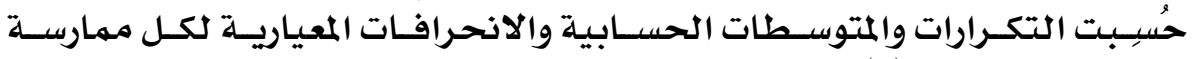

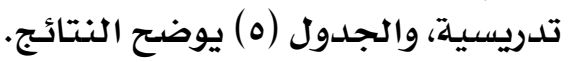

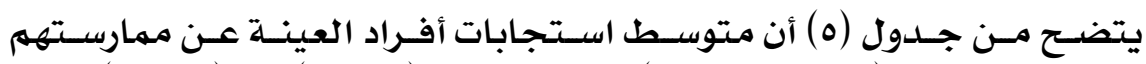

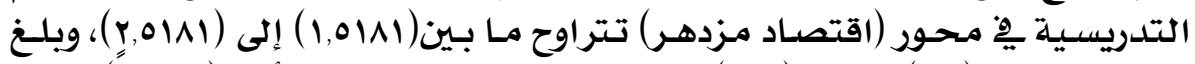

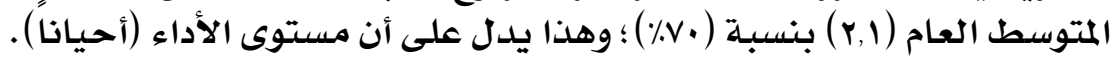

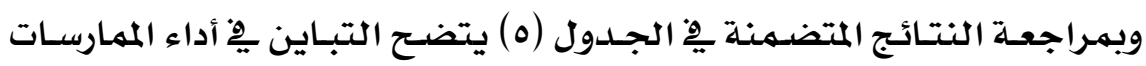

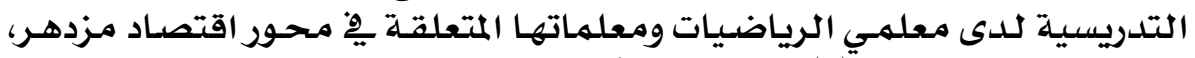

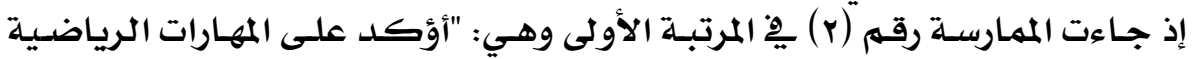

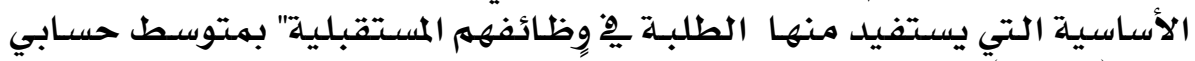

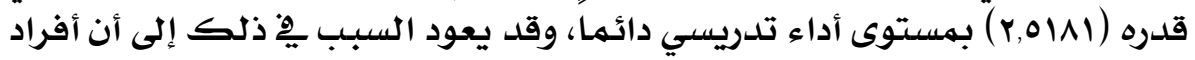

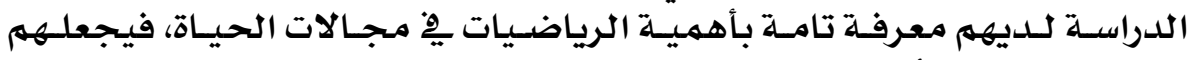

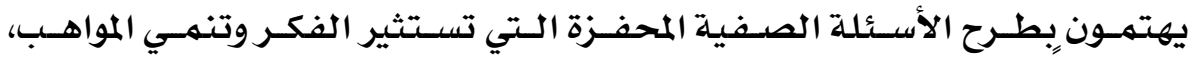

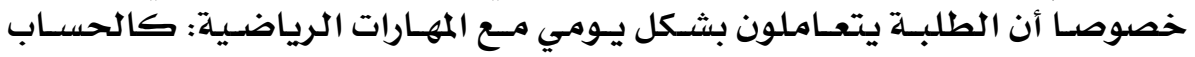

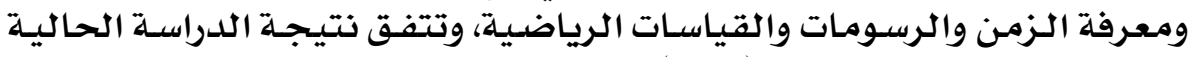

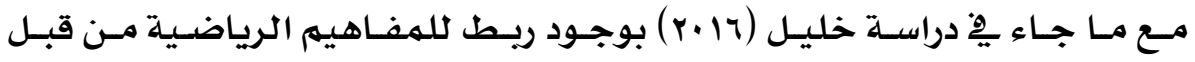

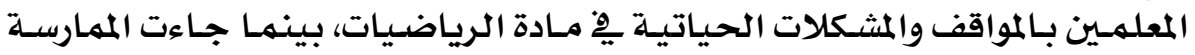

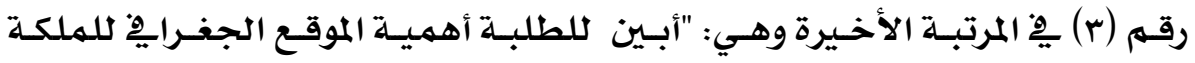

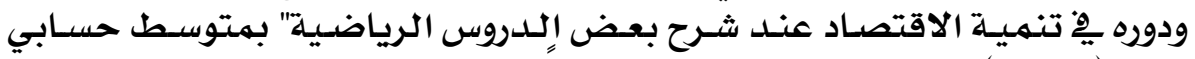

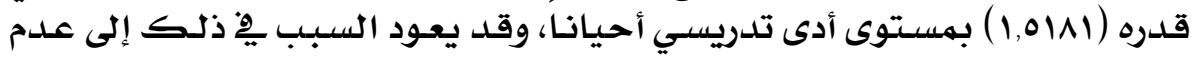

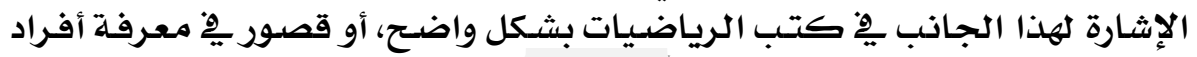

\section{P $q$}




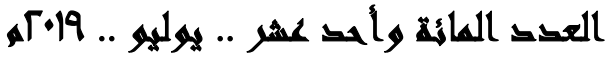

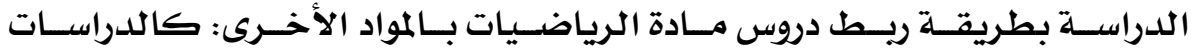

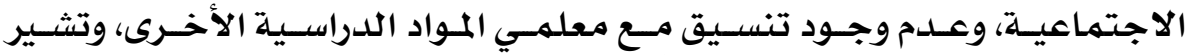

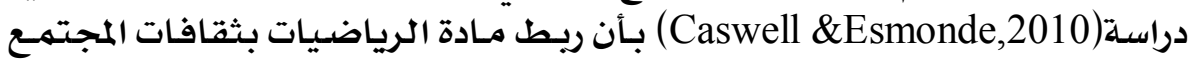

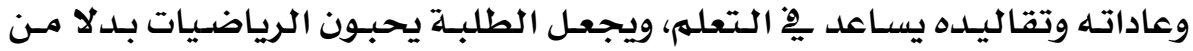

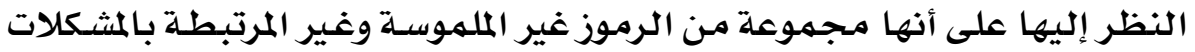

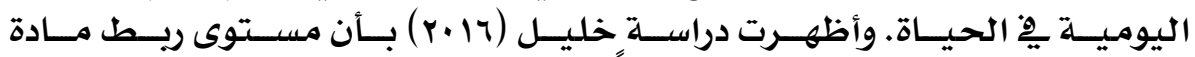

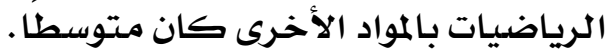

جلدول (ه): مستوى الممارسات التدريسية لمعلمي الرياضيات ومعلماتها فِ محور(اقتصاد مزدهر) من

\begin{tabular}{|c|c|c|c|c|c|c|c|c|}
\hline \multirow[b]{2}{*}{ مستوى الاداء } & \multirow[b]{2}{*}{ الالحياري اف } & \multirow[b]{2}{*}{ متوسط الاداء } & \multicolumn{4}{|c|}{ مستوى الأداء } & \multirow[b]{2}{*}{ الممارست } & \multirow[b]{2}{*}{$\hat{\imath}$} \\
\hline & & & لا أقوم & نادراً & أحياناً & دائماً & & \\
\hline أحياناً & ;,99109 & I,VYra & 11 & $r r$ & rq & rI & 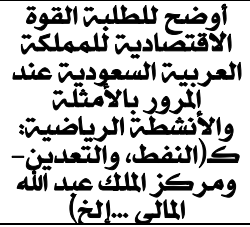 & 1 \\
\hline دائماً & $\because$ VO\&AO & Y,O1AI & $r$ & $v$ & r. & of & 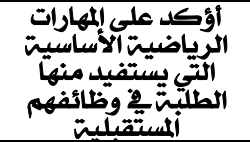 & r \\
\hline أحياناً & 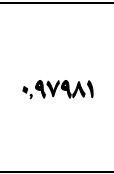 & 1,0111 & $1 \varepsilon$ & YV & rV & 10 & 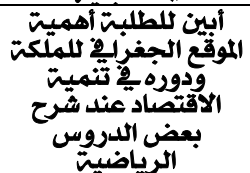 & $r$ \\
\hline أحياناً & $\bullet, \wedge 9 \cdots \wedge$ & Y.1074 & $\varepsilon$ & 10 & $Y \Lambda$ & rq & أثزئاء ألتعلم العمل لدى الحر & $\varepsilon$ \\
\hline أحياناً & •,^乏१०\& & Y,YEI. & $\varepsilon$ & 1. & M & rA & ألمزادرة للعي الطلبت التطلي & 0 \\
\hline دائماً & •,А.Y৭० & 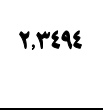 & $r$ & 11 & r & $\varepsilon \varepsilon$ & 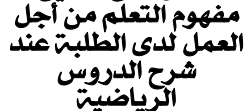 & 7 \\
\hline أحياناً & ,9Y乏1. & $Y, 1 \cdots \wedge \varepsilon$ & 1 & ir & r. & $r \varepsilon$ & 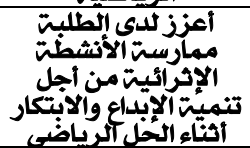 & 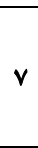 \\
\hline أحيانا & 1,-s9rr & $Y, M \cdot V$ & 11 & 1 & rr & $\varepsilon r$ & 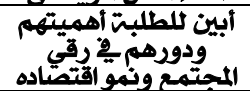 & $\wedge$ \\
\hline أحياناً & $\bullet, 9 V \cdot \varepsilon V$ & r.998 & $\wedge$ & 11 & rq & ro & 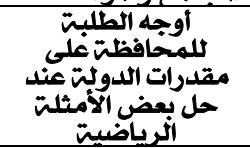 & 9 \\
\hline & أح & $r, 1$ & & & & & المتوسط & \\
\hline
\end{tabular}




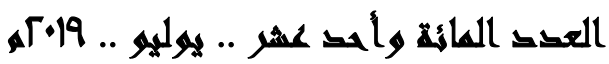

• ثالثاً: النتائج المتعلقة بالسؤال الثالث:

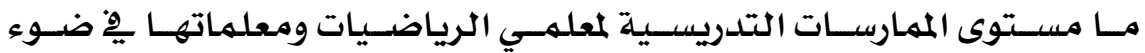

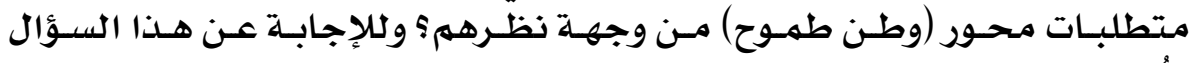

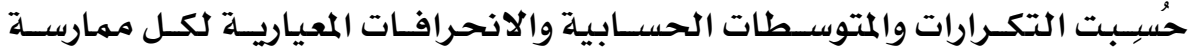

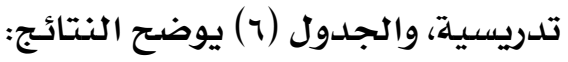

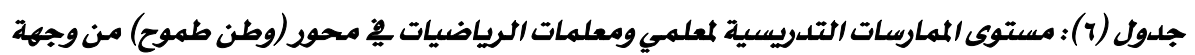
نظرهم:

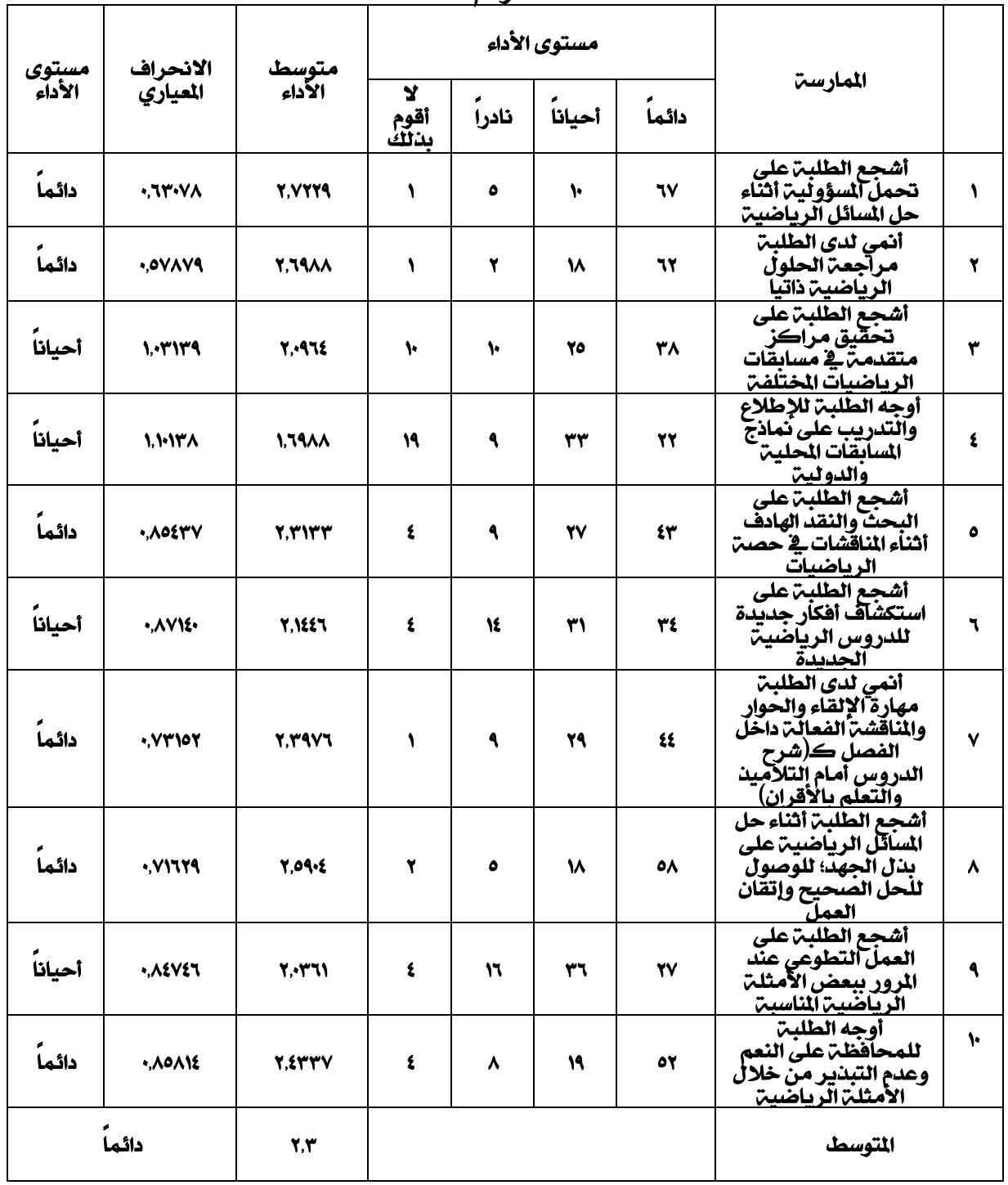




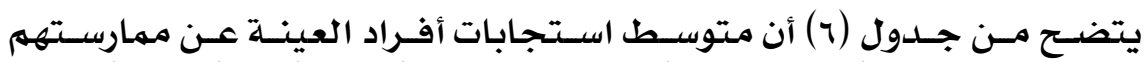

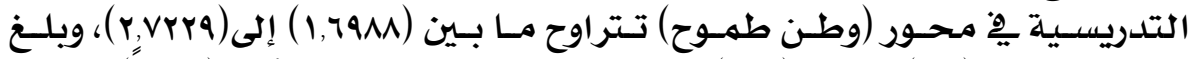

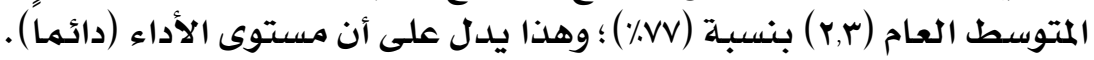

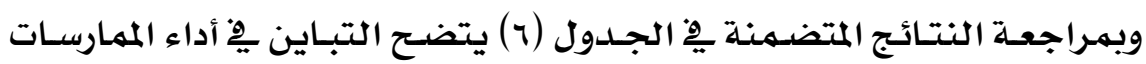

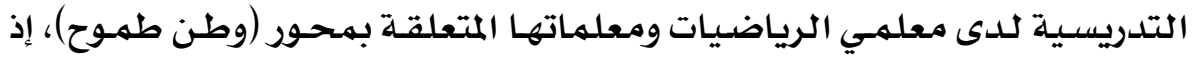

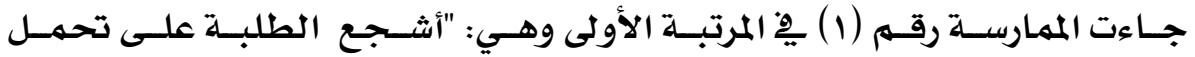

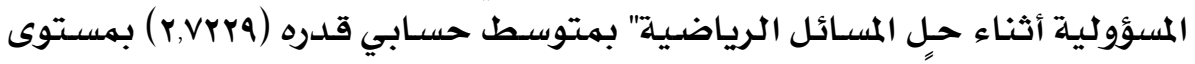

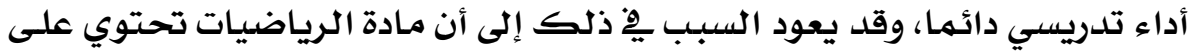

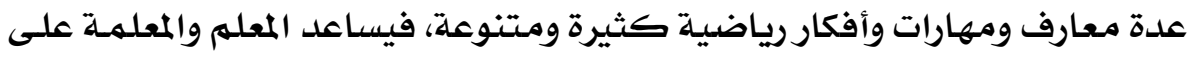

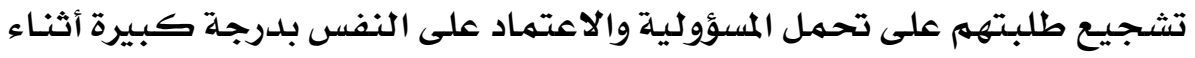

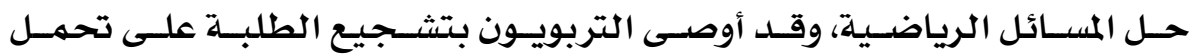

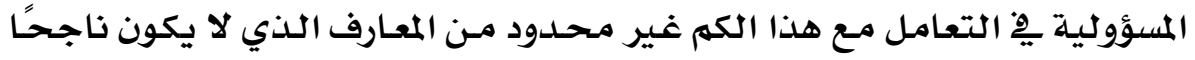

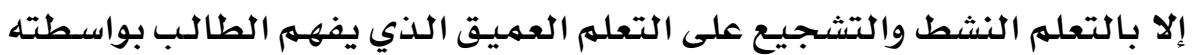

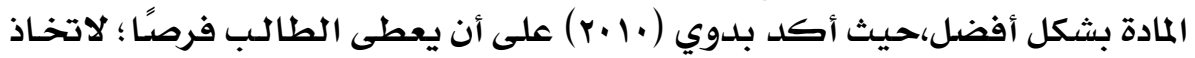

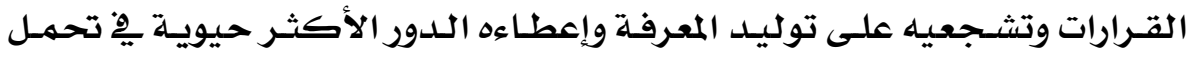

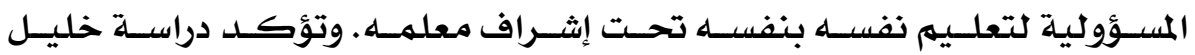

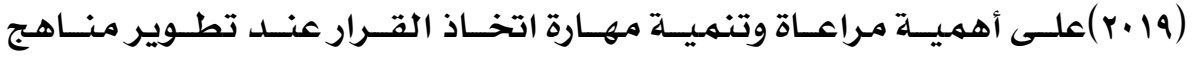

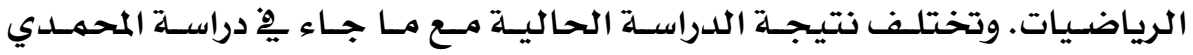

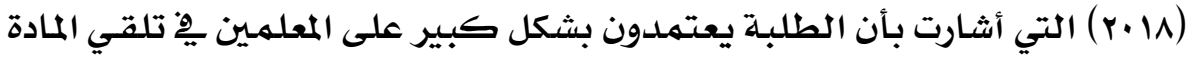

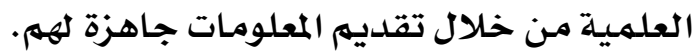

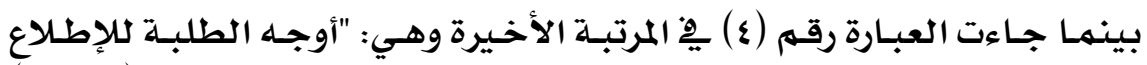

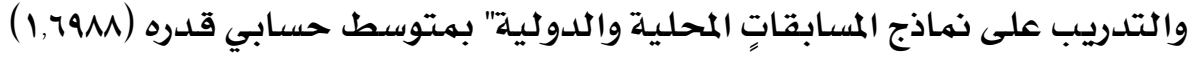

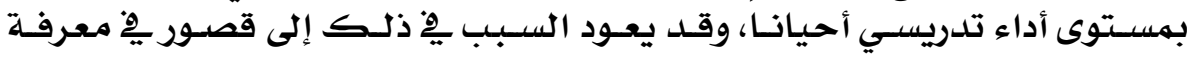

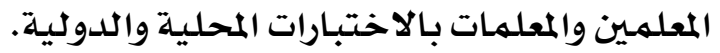

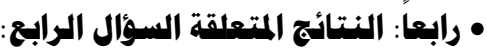

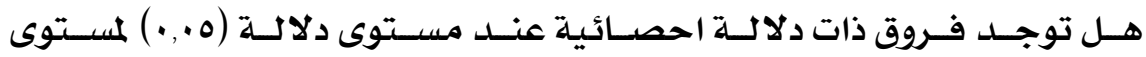

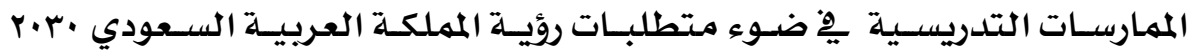
تعزى لمتغيري (الجنس والخبرة التبستوة التدريسية)

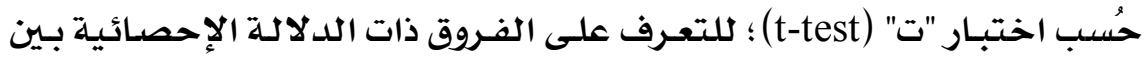

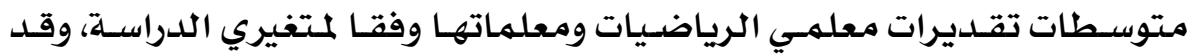

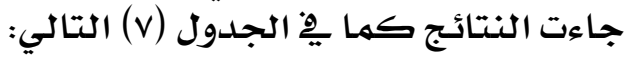




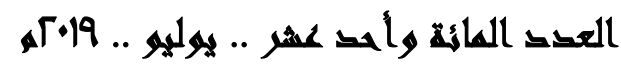

جلدول (v) اختبار"ت" لعينتين مستقلتين (t-test) للتعرف على الفروق بين أراء أفراد العينة وفقاً يتغيري (الخبرة التدريسية- الجنسق)

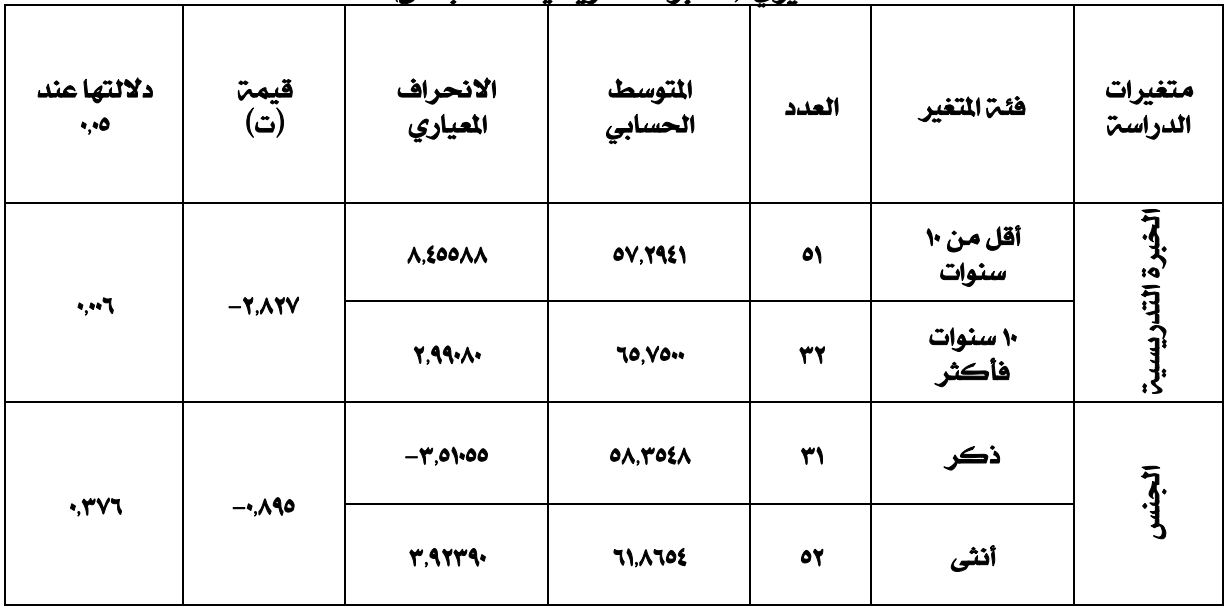

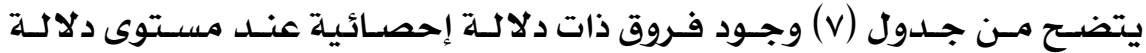

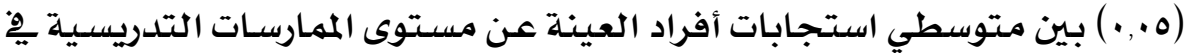

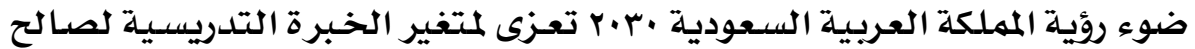

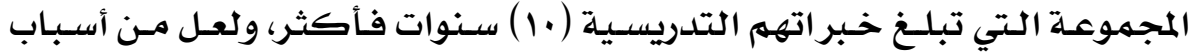

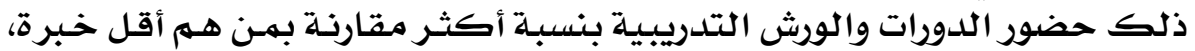
وكذلك التعرض لمواقف تدريسية أكثر، فكلهـا كان عدد الخـبرات التدريسيـية

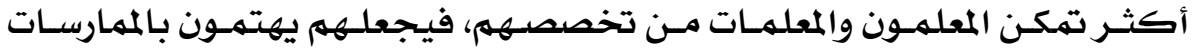

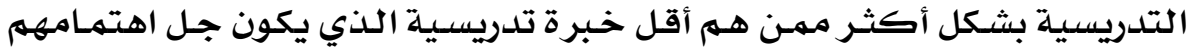

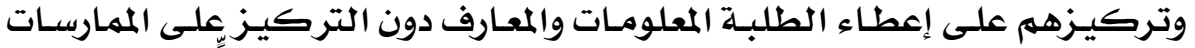

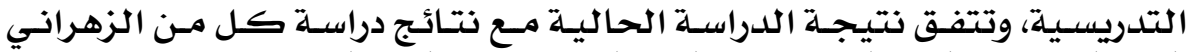

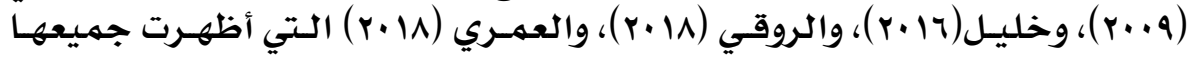

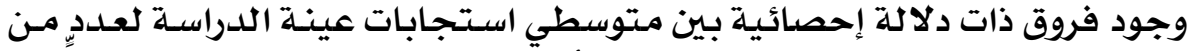

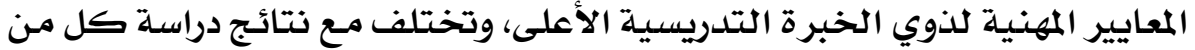

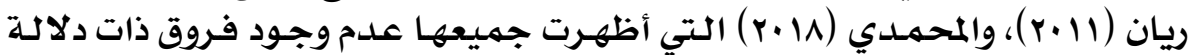

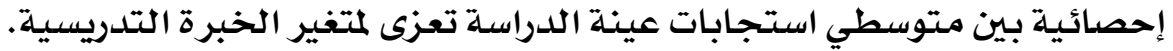

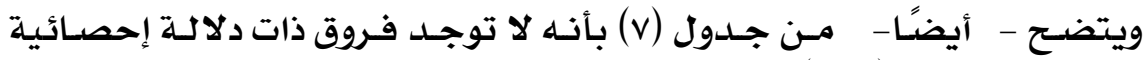

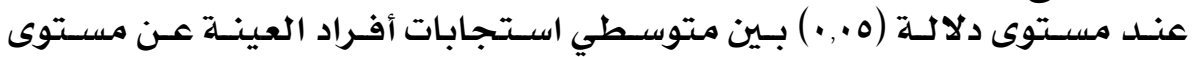

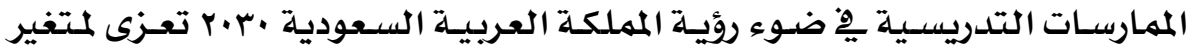

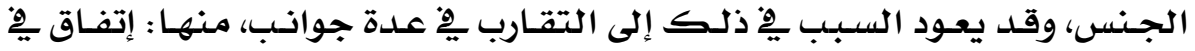

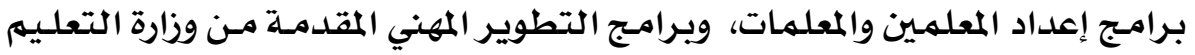

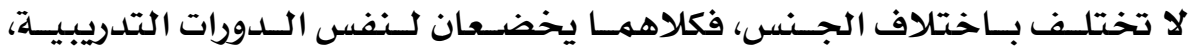




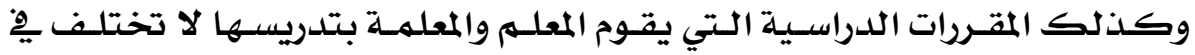

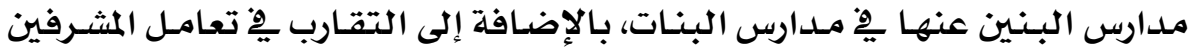

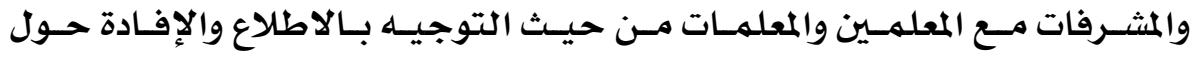

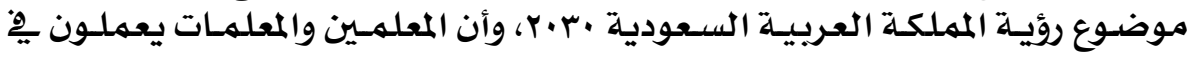

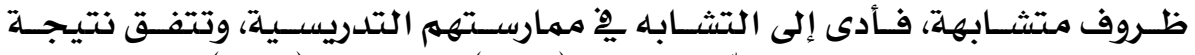

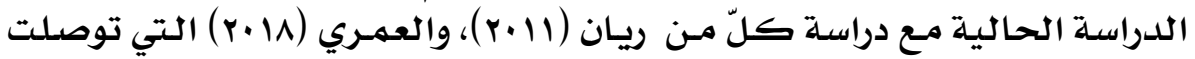

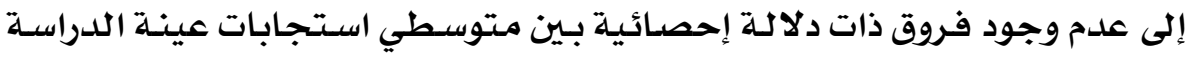
تعزى لمتغير الجنس.

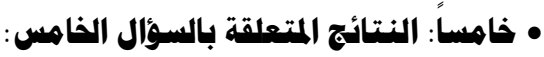

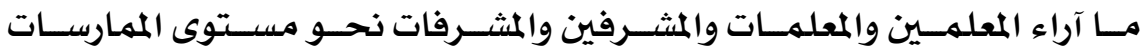

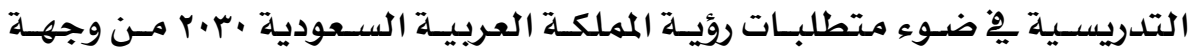
نظرهم؟

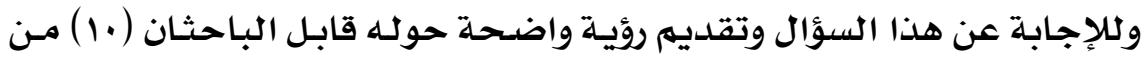

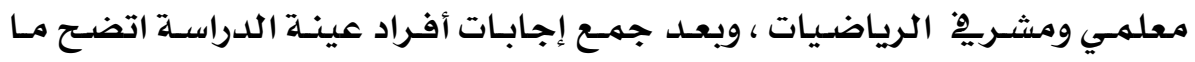
يلي:

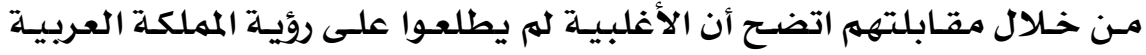

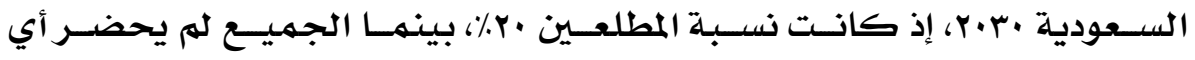

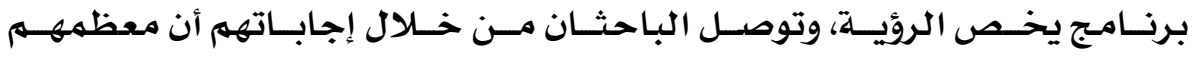

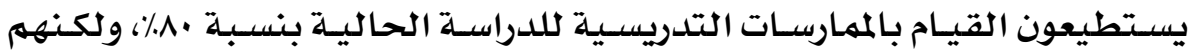

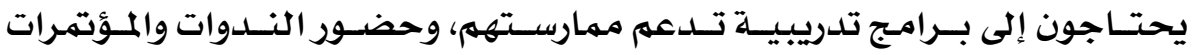

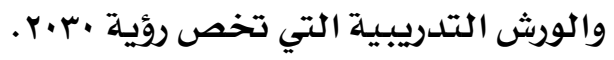

وذكر مـجموعـة مـن أفراد العينـة [نركز على الكتب الملدرسيـية بنسبـة كبيرة

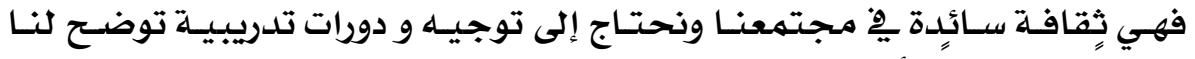

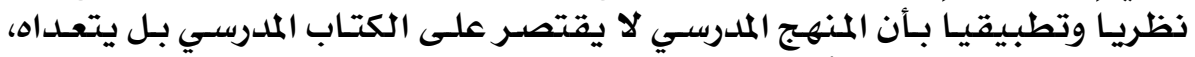

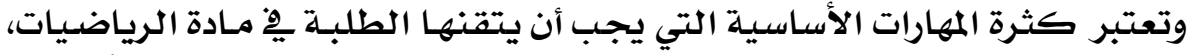

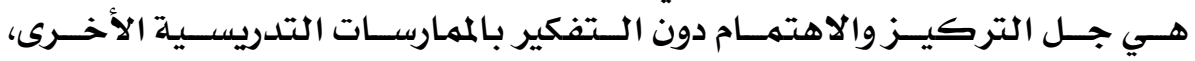

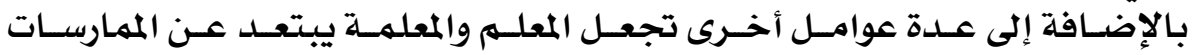

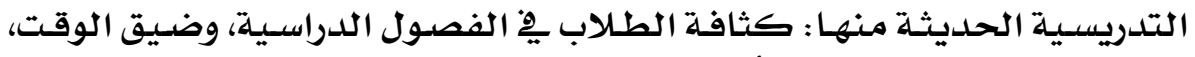

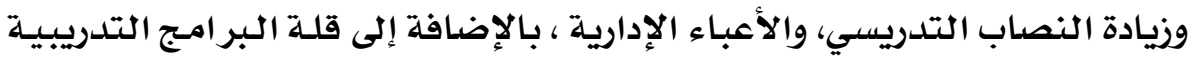

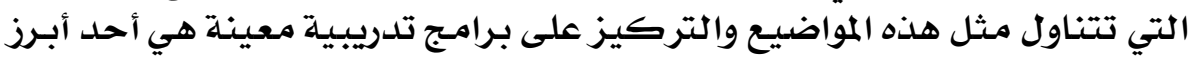

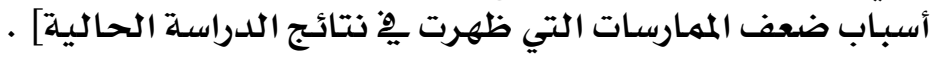

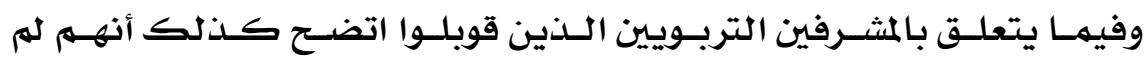

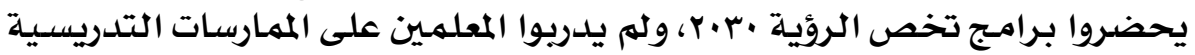




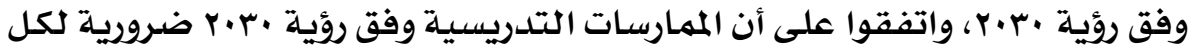

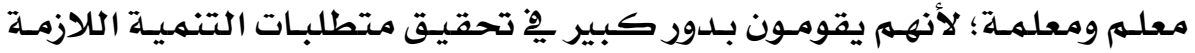

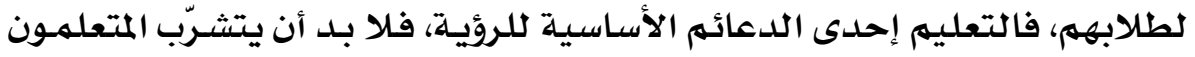

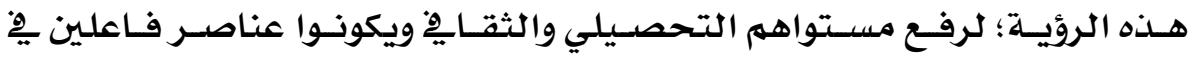
مجتمعهمه. • التوصيات: بناء على النتائج السابقة، فيمكن التوصية بها يلي :

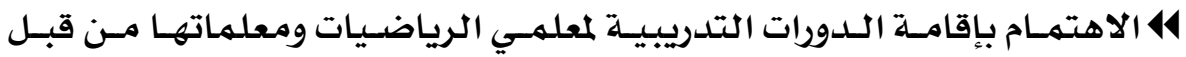

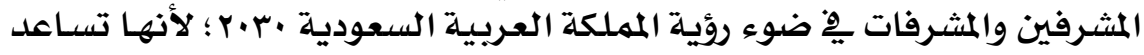

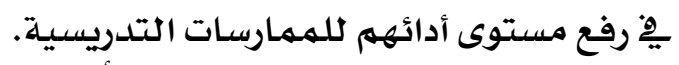

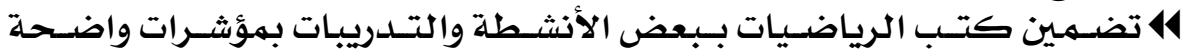

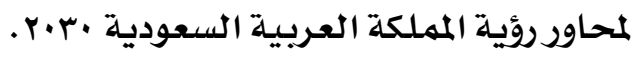

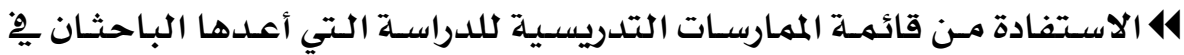

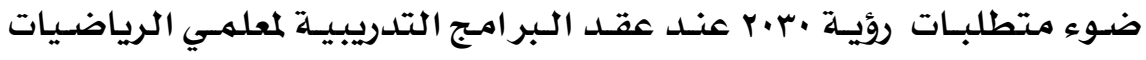

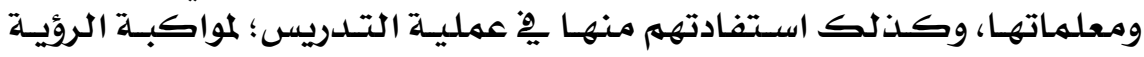
.r.r.

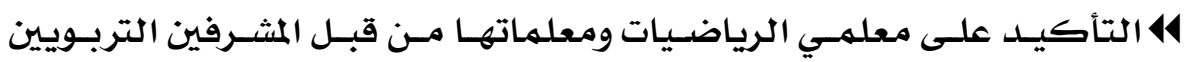

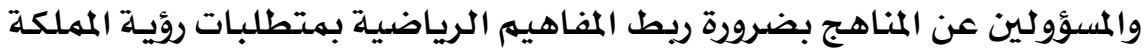

استكمالا للدراسـة الحالية يقترح الباحثان إجراء الدراسـات الآتية:

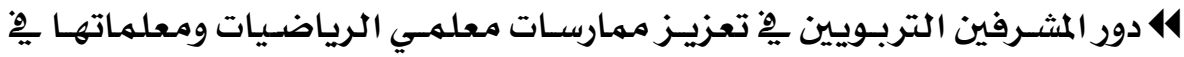
ضواء رؤية المملكة .r.r.r.

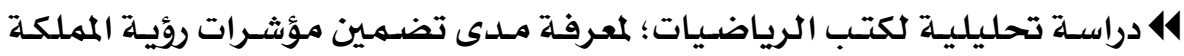
r.r.

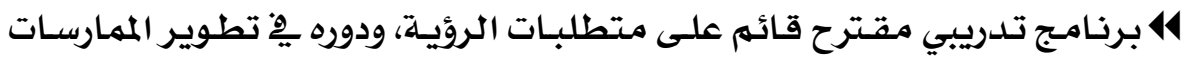

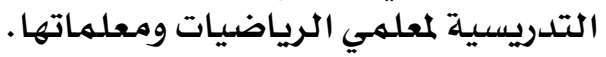

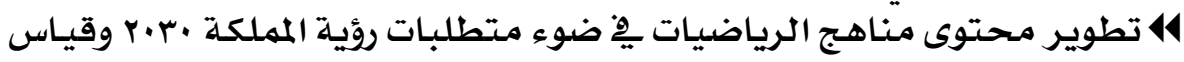
أثرها.

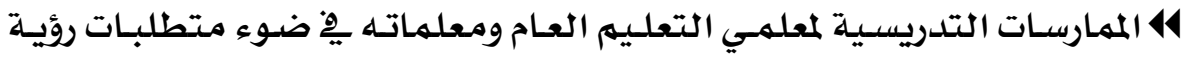

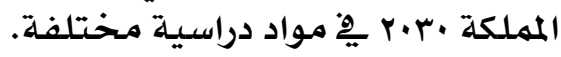

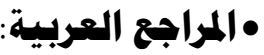

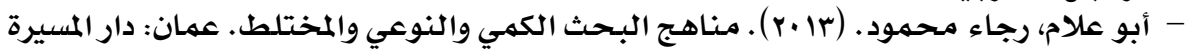
للنشروالتوزيع والطباعة. 


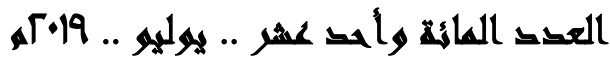

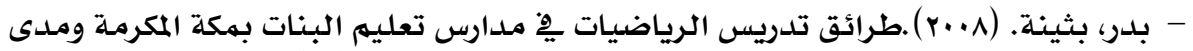

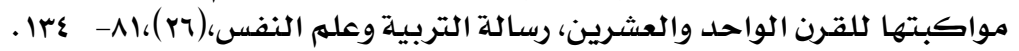

$$
\text { - بدوي، رمضان.( • +r) .التعلم النشط، عمان: دار الفكر. }
$$

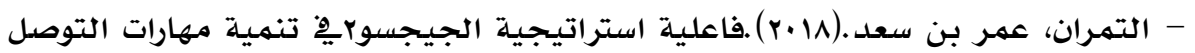

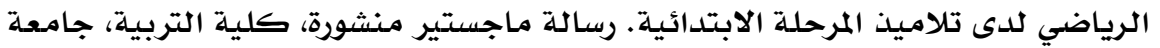

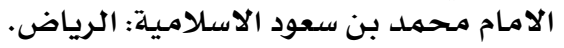

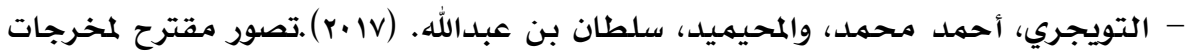

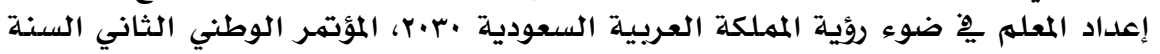
التحضيرية يِ الجامعات السعودية.

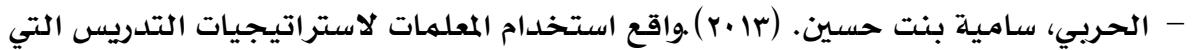

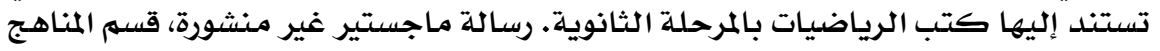

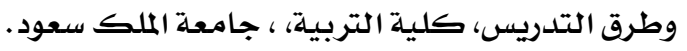

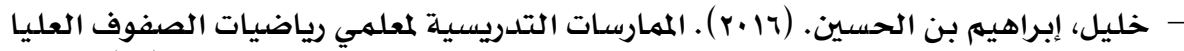

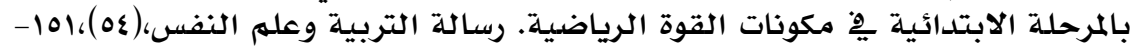
.IVY

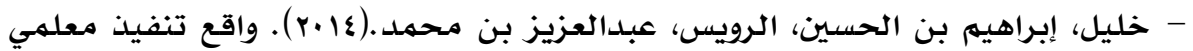

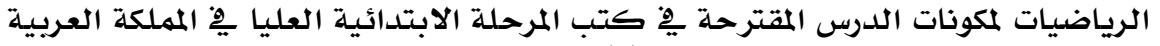

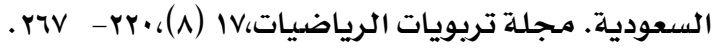

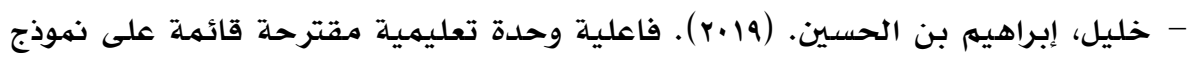

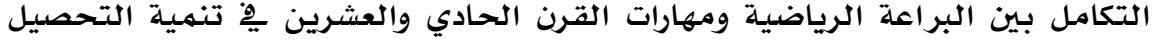

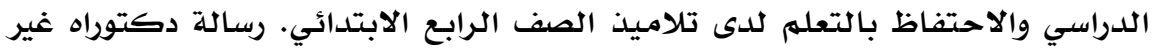

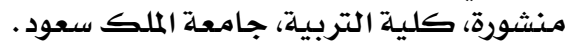

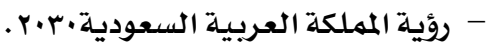

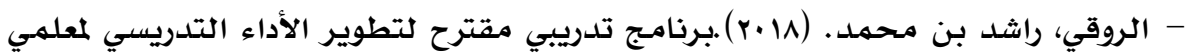

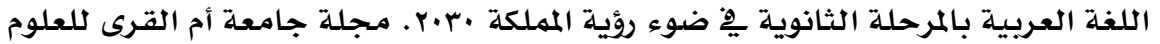

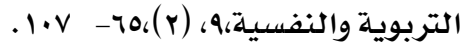

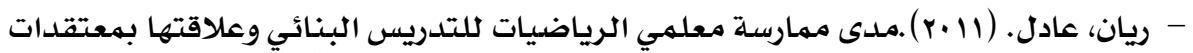

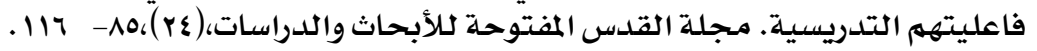

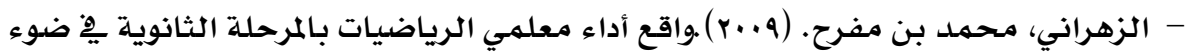

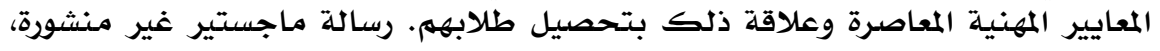

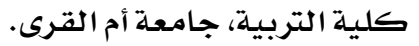

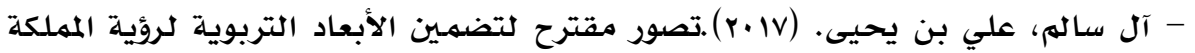

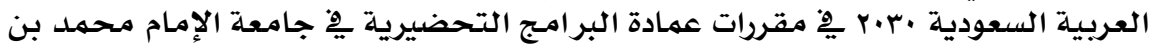

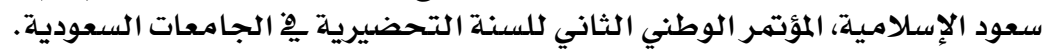




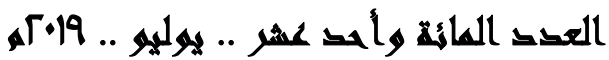

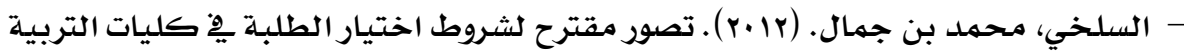

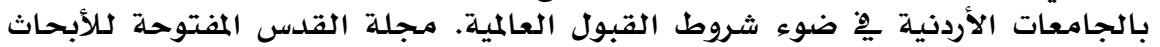

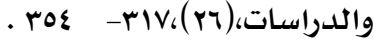

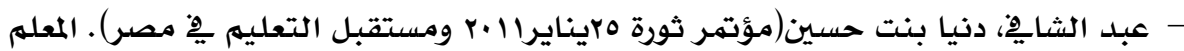

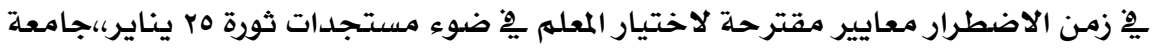

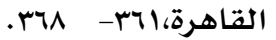

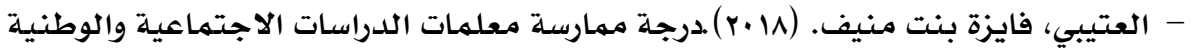

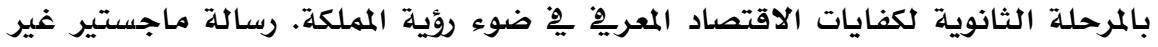

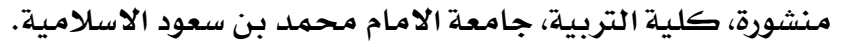

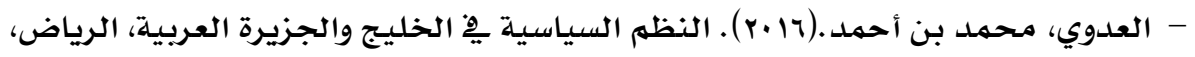
دار الزهراء.

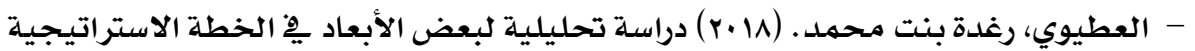

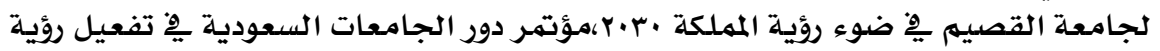
$r \cdot r \cdot$

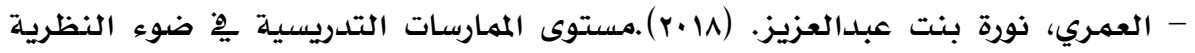

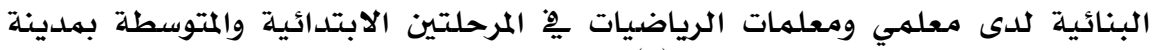

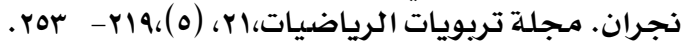

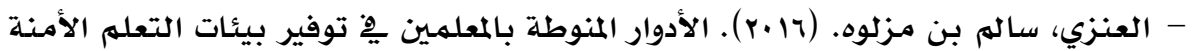

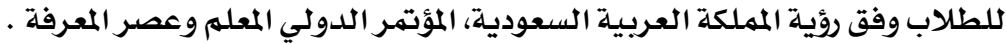

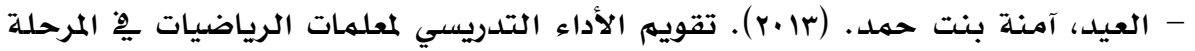

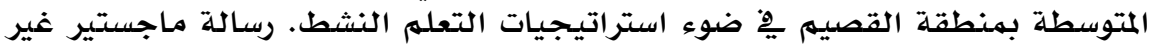
منشورة، كلية التربية،، جامعة القصدئه القصيه.

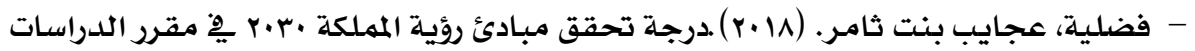

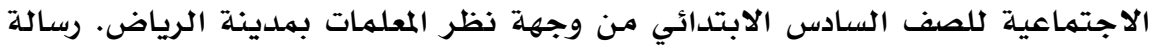

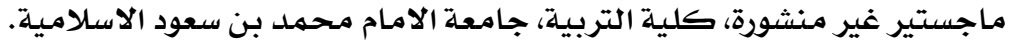

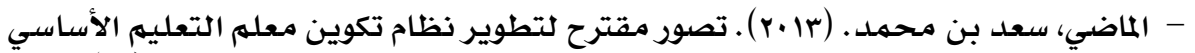

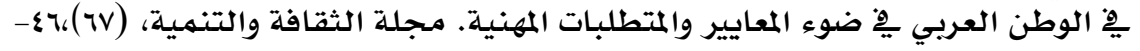

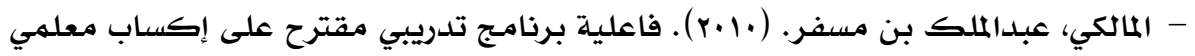
الرياضيات بعض مهارات التعلهم النشط وعلى تحصيل واتجاهات طلابهم نحوها. رسالة

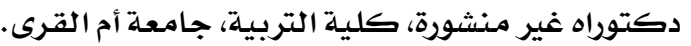

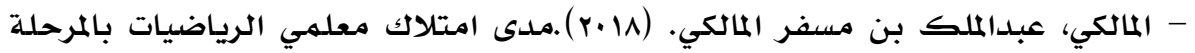

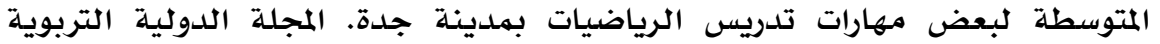




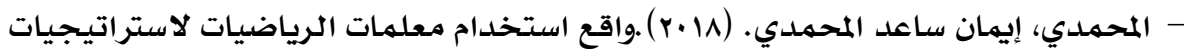

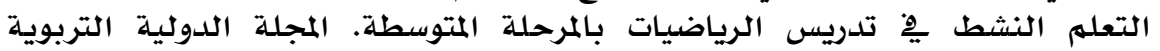

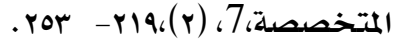

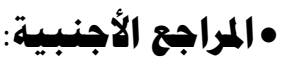

-Avariar C (2013).The Social Math Literacy Project: A Professional Development That Scaffolds Teaching Open-Ended Math Problems With An Emphasis In Social Justice"، a topic for master degree، California university، USA.

-Aguirre ‘J; Turner، E; Bartell، T; Kalinec-Craig، C; Foote، M; Mcduffie، A; DrakerC.(2012). Making Connections in Practice: How Prospective Elementary Teachers Connect to Children's Mathematical Thinking and Community Funds of Knowledge in Mathematics Instruction"،Journal of Teacher Education 64(2)178 192.

-Caswell، B \&Esmonde، I. (2010) .Teaching Mathematics for Social Justice in Multicultural، Multilingual Elementary Classrooms"، Canadian Journal Of Sciencer Mathematics And Technology Education، 10(3)، 244-254.

\section{潾潾溇潾}

